\title{
Article \\ Simulation of the Immunity Test of a Photovoltaic System Disturbed by Electromagnetic Voltage Surge
}

\author{
Dorota Bugała $^{1}\left(\mathbb{D}\right.$, Artur Bugała ${ }^{1, *}$ and Wojciech Machczyński ${ }^{2}$ \\ 1 Institute of Electrical Engineering and Electronics, Faculty of Control, Robotics and Electrical Engineering, \\ Poznan University of Technology, Piotrowo 3A, 60-965 Poznan, Poland; dorota.bugala@put.poznan.pl \\ 2 Polytechnic Faculty, Calisia University, Nowy Świat Street 4, 62-800 Kalisz, Poland; \\ wojciech.machczynski@put.poznan.pl \\ * Correspondence: artur.bugala@put.poznan.pl; Tel.: +48-61-665-2382
}

check for updates

Citation: Bugała, D.; Bugała, A.;

Machczyński, W. Simulation of the Immunity Test of a Photovoltaic System Disturbed by Electromagnetic Voltage Surge. Energies 2021, 14, 3646 https://doi.org/10.3390/en14123646

Academic Editors: Idiano D'Adamo and Andrea Mariscotti

Received: 25 March 2021

Accepted: 16 June 2021

Published: 18 June 2021

Publisher's Note: MDPI stays neutral with regard to jurisdictional claims in published maps and institutional affiliations.

Copyright: (c) 2021 by the authors. Licensee MDPI, Basel, Switzerland. This article is an open access article distributed under the terms and conditions of the Creative Commons Attribution (CC BY) license (https:/ / creativecommons.org/licenses/by/ $4.0 /)$.

\begin{abstract}
This paper presents a computer simulation model (in the MATLAB/Simulink environment) of a photovoltaic system disturbed by a $1.2 / 50 \mu$ s voltage surge pulse, while operating as part of the fixed system of an intelligent building. The tested part of the system consisted of a single PV module and a single-phase DC/AC voltage source converter provided with a maximum power point tracking system. The simulation of the test performed in accordance with the IEC 610004-5 standard required the development of a model of a surge waveform generator and a model of a coupling/decoupling network. The $1.2 / 50 \mu$ s voltage surge pulse was introduced into the system from the power grid side. During the test significant changes in the value of the AC voltage and current were found in the DC/AC converter system. The results of the computer simulation tests were verified with measurements performed in an accredited electromagnetic compatibility laboratory using the instructions specified in IEC 61000-4-5. The MATLAB/Simulink environment was proved as a useful tool of the assessment of effects of conducted electromagnetic disturbances on electronic/electric devices.
\end{abstract}

Keywords: electromagnetic compatibility; $1.2 / 50 \mu$ s voltage surge pulse; photovoltaic installation model; on-grid inverter; EMC simulations

\section{Introduction}

The rapid development of the electronics industry at the turn of the last twenty years has been caused the issue of electromagnetic compatibility (EMC) plays a very important role.

Pursuant to the electromagnetic compatibility directive [1], every electric or electronic product placed on the market must fulfil the requirements of general and subject standards. The equipment manufacturer is required to assess the product's compliance with the standards. The essential product evaluation requirements include:

(a) An electrical or electronic device must not generate electromagnetic disturbances above a level that would cause incorrect operation of other devices in this electromagnetic environment,

(b) An electrical or electronic device should have such a degree of immunity to electromagnetic disturbances that causes its properly operation during use [2-4].

The testing of individual components of the system does not provide a guarantee that the complete system will be electromagnetically compatible [5]. This is caused by the fact that each system operates under separate conditions and is exposed to different disturbances (the impact of more than one disturbance on a given device at the same time is possible). In the literature, many electromagnetic disturbances are described, but one of the most dangerous for electrical and electronic devices is voltage surge. This disturbance has impulsive character and is mainly caused by atmospheric discharges (high energetic), both direct and indirect, or switching transient in the power grid [6]. 
The immunity of a device or system to electromagnetic disturbances is defined as its ability to function properly, when exposed to specific electromagnetic disturbances. Immunity tests of electrical and electronic devices are carried out on the basis of the recommendations contained in the standards. These tests are: immunity to RF disturbances, burst immunity test, surge immunity test, and voltage dips immunity test.

Standard IEC 61000-4-5: 2014 + A1: 2017 “Electromagnetic Compatibility (EMC)Testing and measurement techniques-surge immunity test" [7] presents requirements, test methods, and admissible levels for testing electrical and electronic devices disturbed by voltage surges resulting from switching and transient occurring in the power grid.

Such phenomena may cause not only disturbance of the functionality of equipment, appliances and devices but also damages to internal components and may consequently lead to loss of function. These tests described in [7] apply to different environments and installation conditions.

Tests of electrical and electronic equipment immunity to electromagnetic voltage surges are high-energy tests. During the occurrence of a disturbing impulse in the system, the current can reach or exceed $100 \mathrm{~A}$. This value of current even short term can cause damage of the equipment under test (EUT). As a result of surge impact, the integrated circuits on the circuit boards or wiring can be thermally damaged.

In view of the considerable difficulties in the performance of tests at the place of installation of these kinds of device, their isolation from the impact of external electromagnetic fields and the risk of damage to or even destruction of the devices along with the difficulties, which are encountered (due to the complexity of calculations) during attempts at the analytical description of the phenomena related to the electromagnetic compatibility, the use of computer simulation tools is becoming more and more frequent. In the literature, a simulation approach is encountered using, for example, MATLAB and Simulink software to analyze the impact of lightning induced effects on small-scale, rooftop, and grid-connected PV systems [6], and observing the current and transient voltage that appear in the photovoltaic system after a lightning strike [8,9]. The main components of a photovoltaic installation are, among others, photovoltaic modules and inverters that convert the DC voltage generated from the module into AC voltage for connection to the power grid. An improved model of the PV module simulation based on a two-diode model is presented in [10], while models of both single and three-phase inverters are presented in $[11,12]$. More and more innovative solutions for photovoltaic installations are found in the literature. In the work [13], a hybrid system, which is a combination of a module being the source of energy and its storage system, was proposed. The system consists of several different DC-DC converters. The first of the converters tracks the maximum power point of the photovoltaic module, while the next regulates the microgrid DC bus voltage. The third converter is bidirectional and allows control of the energy flow in the system, including battery charging and discharging. In addition, the installation is equipped with a system protecting the batteries against transients (including surges) from the power grid. Photovoltaic installations are exposed to lightning surge. The example of an attacked installation was described in work [14]. A lightning strike took place at two installation points, namely: on the DC side between the solar module and the inverter and on the AC side between the inverter and the substation. Photovoltaic protection measures have also been described in the literature. The article [15] presents the basic requirements for the installation of lightning protection systems for photovoltaic installations described in detail in the relevant legal acts. Additionally, presented are various ways of realization protection circuits against lightning surges for circuits with photovoltaic modules and barriers of this type of solutions. Work [16] describes in detail the use of various computer simulation tools in emerging lightning protection problems. The focus was mainly on the application of the FDTD method used to simulate the protection of complex electrical installations and high voltage overhead lines or wind turbine or telecommunications towers. The use of EMI filters [17] and voltage suppression diodes (TVS), modeled, e.g., in the LTspice environment [18], are also presented. In the article [19], the authors presented a model 
of the surge protection system in direct current circuits, made in the LTspice program, consisting of gas discharge tube and a transient voltage suppressor diode. In addition, the authors present their own combined surge generator system that introduced disturbances to the tested protection circuit.

Large photovoltaic farms in rural areas are also at risk of overvoltages and surges. The work [20] presents the impact of lightning surges on a medium-sized photovoltaic farm. The impact of lightning surge on photovoltaic modules and the systems connected to them were analyzed to demonstrate the risk of damage to the installation and the need for lightning protection of such installation. An installation consisting of four photovoltaic chains with a total of 10,000 modules in a series-parallel arrangement was examined. The module systems were connected with inverters and connected to the power grid. The test also used EMTP-RV software to demonstrate the impact of lightning surges on photovoltaic systems connected to the power grid. Similarly in the article [21], the authors presented a real-scale simulation model to assess the induced over-voltages on long DC cabling loops. Additionally, the proposed model (on a smaller scale) was tested in the laboratory to confirm its correctness. There are no reports on the computer simulation of the impact of conducted voltage surge disturbances $1.2 / 50 \mu$ s on small photovoltaic installations in the literature.

The aim of the paper was to develop a computer simulation model of a photovoltaic system disturbed by a 1.2/50 $\mu$ s voltage surge pulse, while operating as part of the fixed system of an intelligent building. The tested part of the system consisted of a single PV module and a single-phase DC / AC voltage source converter provided with a maximum power point tracking system. A 1.2/50 $\mu$ s voltage surge pulse, generated by a modeled waveform generator was introduced using a modeled coupling/decupling network into the system from the power grid side. Significant changes in the value of the AC voltage and current were found in the DC/AC converter system.

The results of the computer simulation tests conducted in the MATLAB/Simulink environment were verified with measurements performed using a real EUT in an accredited EMC laboratory according to the IEC 61000-4-5.

Good compatibility of simulation and measurement results indicates that the computer simulation can in some cases be an alternative to laboratory EMC tests, especially those where damage or destruction of the EUT is possible.

Completing the work required solving the problems listed below, the solutions to which are elements of novelty:

- Development of mathematical model and simulation in MATLAB/Simulink environment of the generator of disturbing voltage pulses "surge" 1.2/50 $\mu \mathrm{s}$, based on the recommendations contained in the IEC 61000-4-5 standard,

- Performing of a frequency analysis of a 1.2/50 $\mu$ s voltage pulse and explain that the surge waveform exhibits essentially a low frequency content. Thus, the frequencies contained in the considered signal do not affect the changes in the impedance value and the nature of individual elements of the analyzed electrical circuits such as resistors, coils, capacitors, or transistors, which can therefore be treated as ideal ones,

- Development in MATLAB/Simulink of a coupling/decoupling network simulation model for a "surge" 1.2/50 $\mu$ s generator to isolate the impact of generated disturbances on the power grid,

- Development in MATLAB/Simulink environment of simulation model of selected electrical and electronic devices (photovoltaic system consisting of a photovoltaic module and microinverter), which is a component of commonly used, modern stationary installations,

- Simulation analysis of the impact of electromagnetic surge disturbances on electrical parameters and time characteristics of selected installation in MATLAB/Simulink environment,

- Preparation the laboratory stand and carrying out tests in an accredited EMC laboratory allowing experimental verification of the results of computer simulations, 
- Statistical analysis of the obtained results of laboratory tests and computer simulations (not presented in the paper) to determine the degree of applicability of the proposed simulation tools in electromagnetic immunity testing.

\section{Materials and Methods}

\section{Surge Immunity Test}

Standard IEC 61000-4-5-5:2014 + A1:2017 [7] relates to the testing of immunity of electrical and electronic equipment. It describes the test methods and the range of recommended test levels for equipment in the case of unidirectional surges. Such overvoltages are usually caused by lightning or switching activities in a power system.

The main mechanisms for the generation of voltage surges as a result of lightning are as follows:

- Direct lightning strike in an external (outdoor) circuit, which induces voltage as a result of a current flowing through the Earth's resistance or as a result of a current flowing through the impedance of the external circuit,

- Indirect lightning strike (discharge between clouds or to nearby objects) generating electromagnetic field, which induces voltages in the conductors outside and/or inside the building,

- Current flow in the ground (as a result of nearby direct lightning strike), which couples to the common circuit of the installation grounding network.

- The switching activities can take place:

- In main power supply systems like during switching of capacitor banks,

- During changes of power load of distribution network,

- During switching of thyristors connected to resonant circuits,

- During short circuits and arc discharges to grounding installation.

Surges (transients) induced in equipment affected by direct or indirect lightning discharges and switching activities may pose a risk to the integrity of the equipment/system subjected to such electromagnetic interference (EMI).

The purpose of the standard [7] is to establish a reference for assessing the surge immunity of electrical and electronic equipment whose power and connection lines are exposed to high energy disturbances. The standard describes a consistent method for assessing the immunity of equipment or system to the specific electromagnetic phenomenon (conducted disturbance) and defines a range of test levels, test equipment (including wave generators and coupling/decoupling networks), test bench configurations, and test procedures. The standard outlines several levels of test voltages that relate to different environments and operating conditions of the installation.

The objective of this test is to determine the reaction of an equipment under test under specific operating conditions to voltage surges modeling power system switching or lightning effects. It should be noted that this test is not intended to test the quality of EUT insulation at high voltage. Moreover, the standard [7] does not apply in case of direct lightning strikes.

According to the standard, the system under test is in a configuration as similar as possible to the final one. The coupling circuit couples the surge pulse generated by the waveform generator to the EUT whereas the decoupling part is to effectively suppress disturbances propagated towards the mains and auxiliary equipment.

To introduce the form of the disturbance, the waveform of the normalized voltage surge $1.2 / 50 \mu \mathrm{s}$ vs. time is illustrated in Figure 1 with front time $\mathrm{T}_{\mathrm{f}}=1.67 \times \mathrm{T}=1.2 \mu \mathrm{s}$ and duration (time to half value) $\mathrm{T}_{\mathrm{w}}=50 \mu \mathrm{s}$. 


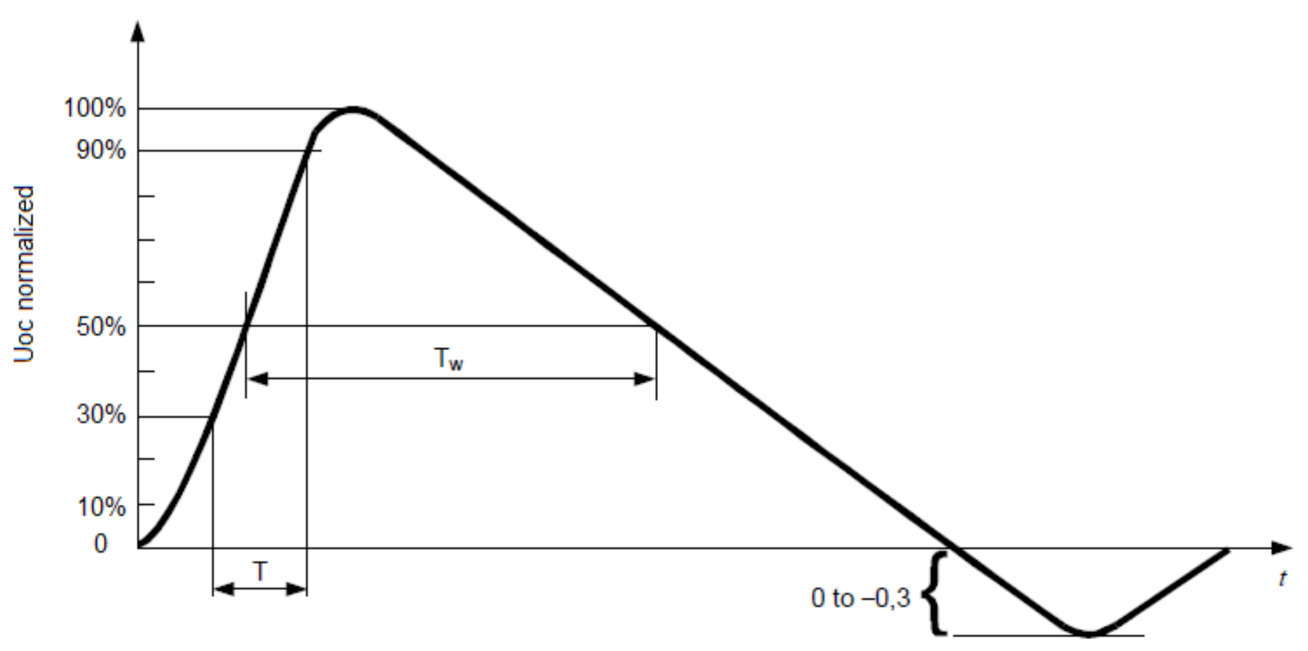

Figure 1. Normalized waveform of a voltage surge [7].

For AC mains voltage with an RMS value of $230 \mathrm{~V}$, the surge voltage impulse is introduced to the tested system at the moment of the mains voltage peak (amplitude). The time between pulses is $1 \mathrm{~min}$. The internal impedance of the pulse generator is $2 \Omega$.

The IEC 61000-4-5 specifies several levels of tests depending on what environment a system is designed for. Table 1 summarizes the magnitudes of surge voltages of different test levels and what these levels mean. It is worth to mention that from the test level 1 and up, the system or equipment requires protection devices to minimize the surge energy entering the internal circuit.

The open circuit test voltage levels are presented in Table 1:

Table 1. Open circuit test voltage levels [7].

\begin{tabular}{ccc}
\hline Level & $\begin{array}{c}\text { Line-to-Line } \\
\mathbf{k V}\end{array}$ & $\begin{array}{c}\text { Line-to-Ground } \\
\mathbf{k V}\end{array}$ \\
\hline 1 & - & 0.5 \\
2 & 0.5 & 1 \\
3 & 1 & 2 \\
4 & 2 & 4 \\
$\mathrm{X}$ & Custom & Custom \\
\hline
\end{tabular}

The test level must be chosen for different installation environments, in particular for classes 1-4. Example Class 2: for electrical environments where the cables are well separated but the earthing system is common to the mains power supply, so that it may be affected by overvoltage generated by the electrical system itself or by lightning. Test level $\mathrm{X}$ is not specified. This level may be specified in the technical requirements for the product.

When voltage surges are applied to the EUT, the test results are categorized into four pass/fail criteria. The reaction of the EUT corresponds to the classification as follows:

- Class A-normal operation of the device during and after occurrence of electromagnetic disturbance;

- Class B-temporary deterioration of the device during the occurrence of the disorder and return to normal operation after the electromagnetic disturbance has ceased;

- Class C - temporary deterioration of the device during the occurrence of electromagnetic disturbance and return to normal operation after operator intervention;

- Class D-permanent deterioration of the device or its destruction.

It is worth noting as a side note that the 1.2/50 $\mu$ s lightning voltage surge known from laboratory practice, commonly used in testing insulation resistance [22-24], is not 
directly related to the voltage prevailing in the lightning channel between the cloud and earth [25-29].

Identifying this surge with the parameters found in the lightning channel is a common mistake even made by experienced researchers who are mainly involved in tests performed in high voltage laboratories and EMC laboratories. Surge 1.2/50 $\mu$ s was adopted in the normative regulations as a consensus, which allows one to hope that it reflects the voltage generated in the analyzed system fairly faithfully during an earth lightning strike.

\section{Results}

\subsection{MATLAB/Simulink Model of a Voltage Surge Immunity Test}

In the MATLAB/Simulink environment, based on the data contained in IEC 61000-4-5, the proprietary model of the voltage surge generator was developed. A double exponential mathematical relation that describes $1.2 / 50 \mu$ s open circuit voltage waveform $\mathrm{u}(\mathrm{t})$, is given by Equation (1) [30].

$$
u(t)=A V_{p}\left[1-\exp \left(\frac{-t}{\tau_{1}}\right)\right] \exp \left(\frac{-t}{\tau_{2}}\right)
$$

where, $t$ is the time in $\mu \mathrm{s}(\mathrm{t} \geq 0), V_{p}$ is the peak value, $A=1.037, \tau_{1}=0.4074 \mu \mathrm{s}$, and $\tau_{2}=68.22 \mu \mathrm{s}$.

The modeled surge pulse waveform with the amplitude $1 \mathrm{kV}$ is presented in Figure 2.

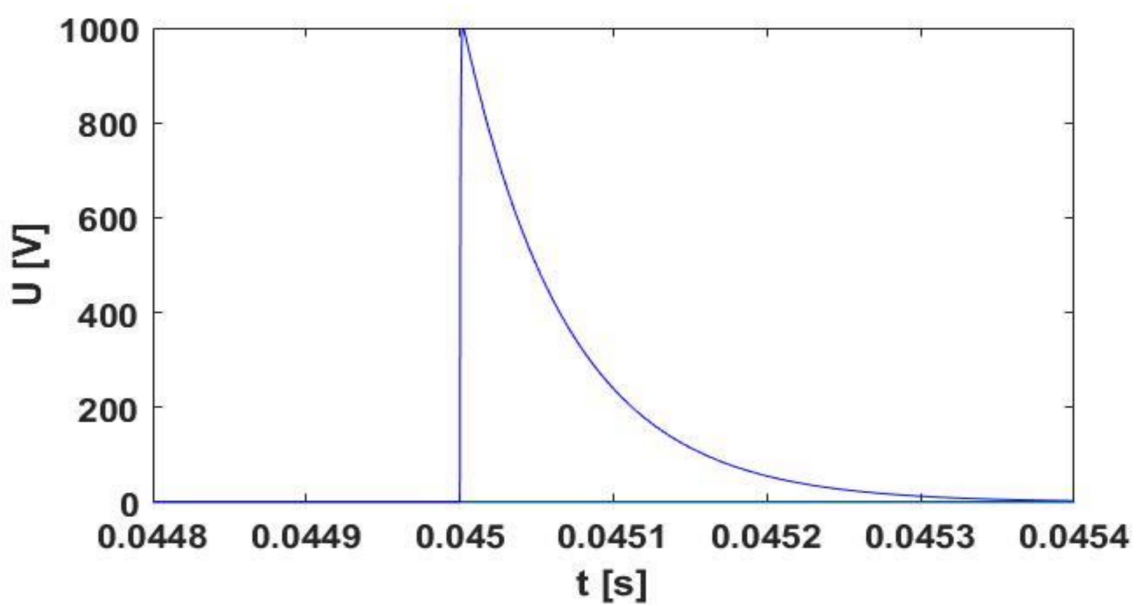

(a)

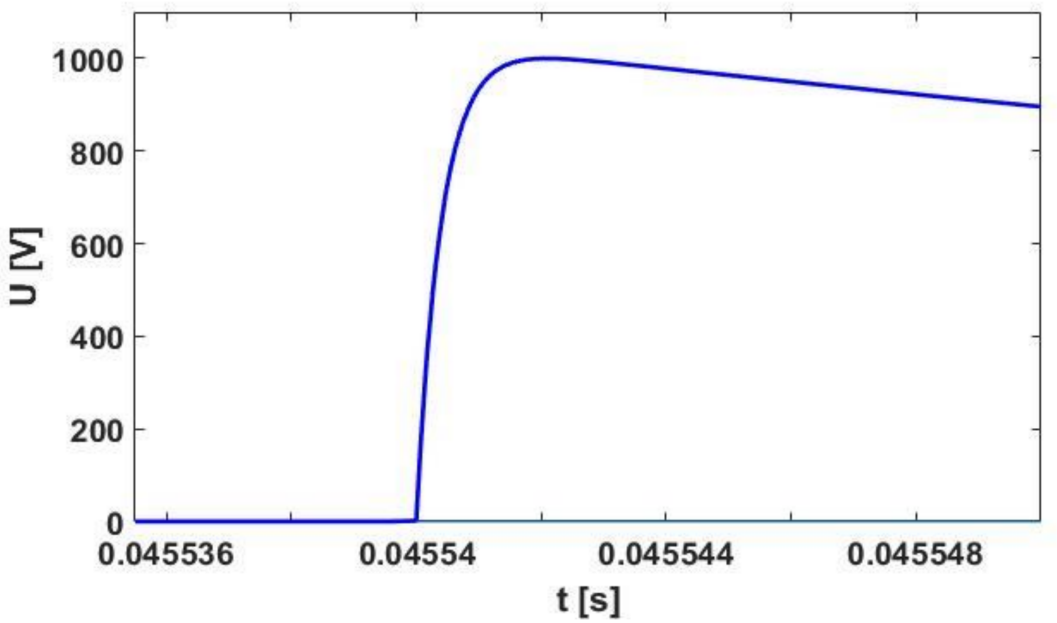

(b)

Figure 2. Voltage surge pulse vs. time: (a) the whole of the generated waveform; (b) view of the fast-changing frontal of the surge pulse. 
Using the MATLAB/Simulink software, the frequency spectrum of the analyzed $1.2 / 50 \mu$ s voltage surge impulse with amplitude $1 \mathrm{kV}$ was determined. The results are shown in Figure 3.

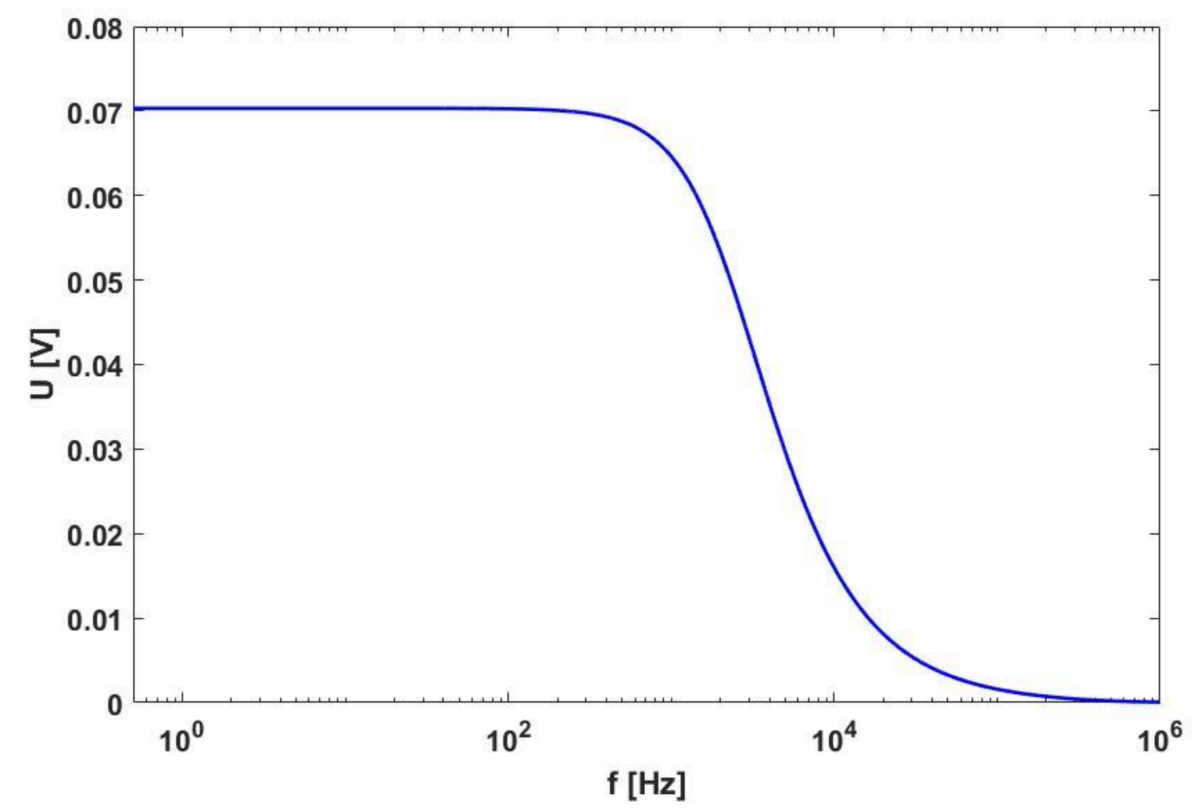

Figure 3. Frequency spectrum of the voltage surge pulse.

The spectrum of the analyzed disturbing signal indicates a frequency range up to maximum several hundred kilohertz. The frequencies contained in the spectrum of the considered signal do not affect the changes in the impedance value and the nature of individual elements of the analyzed electrical circuits such as resistors, coils, capacitors, or transistors, which can therefore be treated as ideal elements.

It is possible to use the rise time of a transient signal to determine the signal's highest frequency of interest, which can be, e.g., used to help select test equipment such as an oscilloscope or a spectrum analyzer.

According to [31] a double-exponential pulse function in the general form:

$$
x(t)=C\left(e^{-\alpha t}-e^{-\beta t}\right) u(t)
$$

can be used to model a number of transient signals (e.g., lightning current, the voltage surge 1.2/50 $\mu \mathrm{s}-$ Equation (1) in our paper, etc.) that contain a single maximum or peak value, whereas $1 / \alpha$ is referred as the fall-time constant and $1 / \beta$ as the rise-time constant.

When the ratio $\beta / \alpha$ is greater than about 4 , then $96 \%$ of the total energy is contained within the second break frequency located at $\beta \mathrm{rad} / \mathrm{s}$. Thus, the highest frequency of interest is probably around $\beta$.

It should be noted that it is not necessary to use sophisticated expressions for the delay and rise time (given in the literature) to determine the highest frequency of interest. When $\beta>>\alpha$, the exponential containing $\beta$ will decay much faster than the exponential containing $\alpha$. Thus, the highest frequency of interest, which is equal to the inverse of this exponential's time constant, will be mainly determined by this faster decaying exponential.

It possible to transform Equation (1) into the general form (2) as shown below:

$$
\begin{aligned}
& A V_{p}\left[1-\exp \left(\frac{-t}{\tau_{1}}\right)\right] \exp \left(\frac{-t}{\tau_{2}}\right)= \\
& =C\left(e^{-\frac{t}{\tau_{2}}}-e^{-\frac{t}{\tau_{1}}} e^{-\frac{t}{\tau_{2}}}\right) u(t)=C\left(e^{-\frac{t}{\tau_{2}}}-e^{-\frac{t\left(\tau_{2}+\tau_{1}\right)}{\tau_{1} \tau_{2}}}\right) u(t)= \\
& =C\left(e^{-\alpha t}-e^{-\beta t}\right) u(t)
\end{aligned}
$$


where:

$$
\alpha=\frac{1}{\tau_{2}} \text { and } \beta=\frac{\tau_{1}+\tau_{2}}{\tau_{1} \tau_{2}}
$$

It is easy to show that if $\tau_{2}>\tau_{1}$ :

$$
\beta=\frac{\tau_{1}+\tau_{2}}{\tau_{1} \tau_{2}}=\frac{1+\frac{\tau_{1}}{\tau_{2}}}{\tau_{1}} \approx \frac{1}{\tau_{1}}
$$

On the basis of the parameter $\beta$ one can define the highest frequency of interest:

$$
\text { highest frequency of interest } \approx \frac{\beta}{2 \pi} \approx \frac{1}{2 \pi \tau_{1}}
$$

Taking into account that for an impulsive signal of $1.2 / 50 \mu \mathrm{s} \tau_{1}=0.4074 \mu \mathrm{s}$, the highest frequency of interest is roughly $391 \mathrm{kHz}$.

\subsection{Photovoltaic System and Its MATLAB/Simulink Model}

The system consisted of a monocrystalline photovoltaic module connected to a singlephase microinverter operating in the synchronization mode with a power grid. The electrical power of the used photoconverter was adapted to the electrical parameters of the applied inverter in terms of the maximization of the energy efficiency of the DC/AC converter and the possibility of the proper implementation of the maximum power tracking algorithm, which, in real conditions, enables the adaptation of the inverter circuit to changing weather conditions. The microinverter was designed for interoperation with one photovoltaic module, which means the number of used DC/AC converters increases in proportion to the number of photovoltaic modules in the case of more powerful systems. The inverter has two major sections: the input section (which contains the filter capacitors that stabilize the DC voltage, and the maximum power point tracking module for the optimization of the value of the generated electrical power dependent on the power of the receiver and the lighting conditions) and the output section (the system of LC elements, which affect the improvement of the electricity quality parameters, surge arresters, and optionally the disconnector section).

The transformer inverter in the input section used for the tests comprises a DC/AC converter in the half-H bridge circuit with a square wave output, including the stabilization and filtration system. After the repeated filtration of the variable component from voltage on the secondary side of the high-frequency transformer, in the full-wave rectifier circuit with a low pass filter, the proper formation of the output voltage in the full-bridge circuit takes place, including further filtration, before synchronization with the power grid. An important advantage of the used two-step inverter is its high efficiency when compared to other converters (dependent on the load and DC voltage levels) and the guarantee of the galvanic isolation of the AC and DC side. The object used for the tests is a grid inverter, which means that it is possible to transmit electricity to the power grid (as opposed to the island inverters operating in dedicated circuits with the function of charging electricity storages). The grid inverter, in the event of power failure, is switched off, which is the result of the application of protection against island operation, and thus protection against potential electric shocks to operating staff [32-34].

The model of the analyzed system was provided in the MATLAB/Simulink environment. The diagram of the test system is presented in Figure 4. 


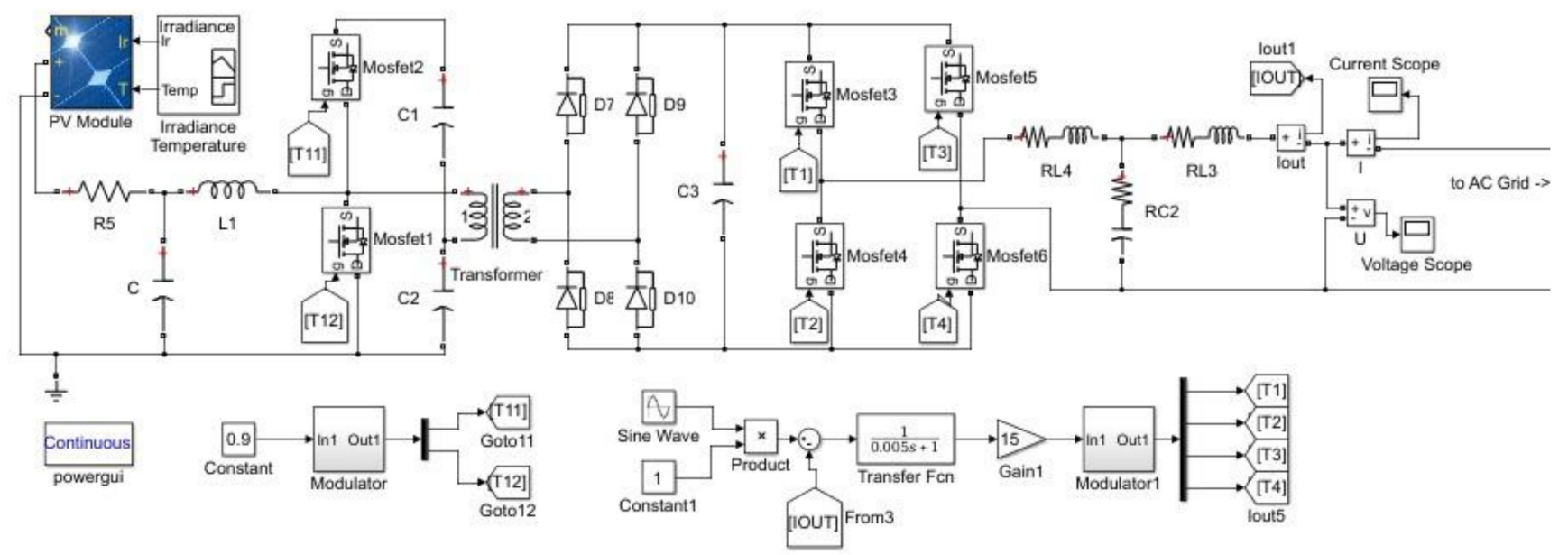

(a)

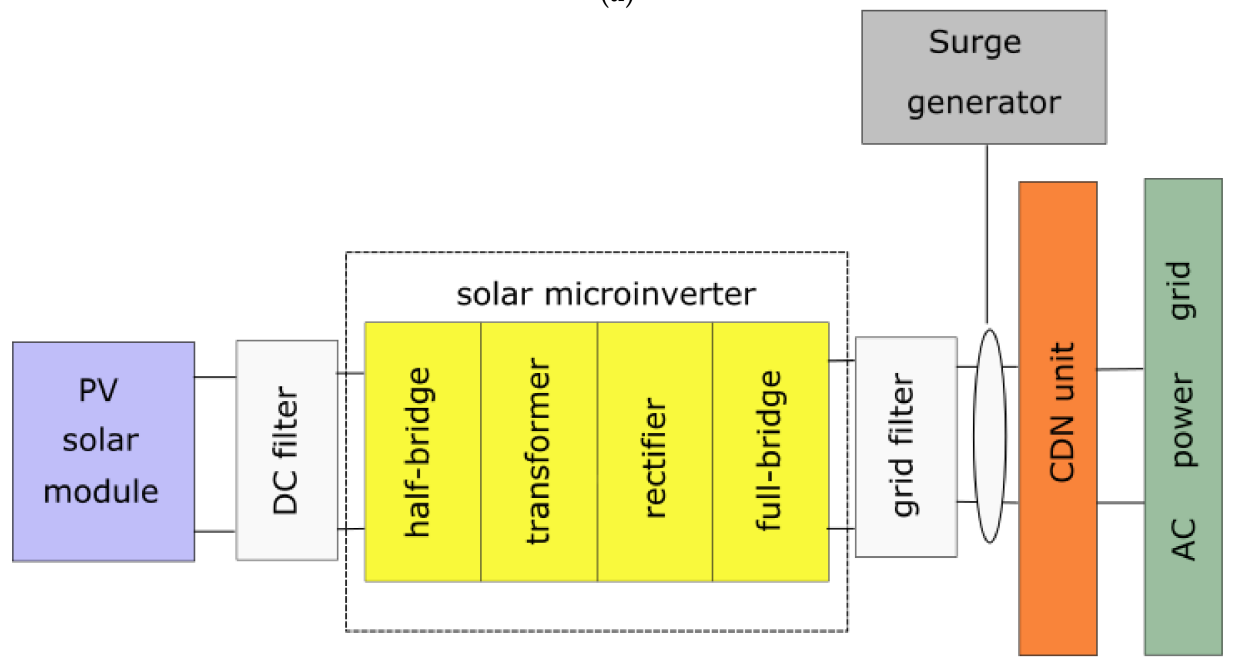

(b)

Figure 4. The structure of the tested system consisting of a photovoltaic module with a microinverter: (a) Detailed description. (b) Block description.

The values of parameters in grid filter and in the filter located in DC system side are presented in Table 2.

Table 2. Values of elements in filter blocks.

\begin{tabular}{|c|c|}
\hline Element & Value \\
\hline R5 & $0.1 \Omega$ \\
\hline L1 & $25 \mu \mathrm{H}$ \\
\hline $\mathrm{C}$ & $100 \mu \mathrm{F}$ \\
\hline \multirow{2}{*}{ RL4 } & $0.5 \Omega$ \\
\hline & $220 \mu \mathrm{H}$ \\
\hline \multirow[b]{2}{*}{ RL3 } & $0.5 \Omega$ \\
\hline & $1 \mathrm{mH}$ \\
\hline \multirow{2}{*}{ RC2 } & $0.5 \Omega$ \\
\hline & $1 \mu \mathrm{F}$ \\
\hline
\end{tabular}

\subsection{MATLAB/Simulink Model of a Coupling/Decupling Network and Surge Generator}

A coupling/decoupling network (CDN) is another integral part of the test setup. The $\mathrm{CDN}$ is an electrical circuit, interconnected between the EUT and the auxiliary equipment 
(AE) to force the injected signal to flow through the EUT preventing the damage or malfunction of the AE. The component values of this impedance are specified by the standard [7]. The layout of the model, which is used for the surge immunity tests, is depicted in Figure 5.

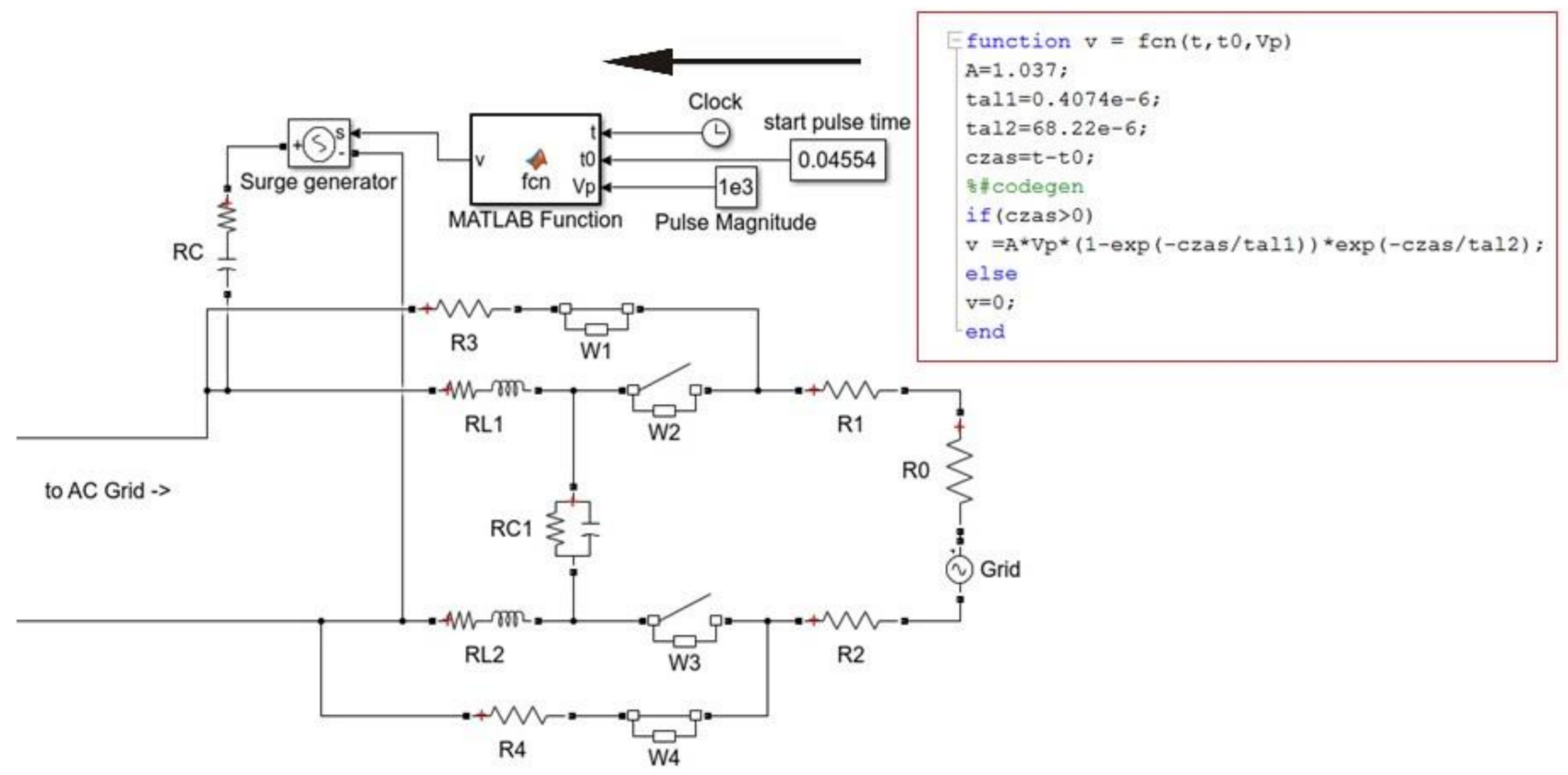

Figure 5. CDN model and surge generator implementation for the immunity test.

W1, W2, W3, and W4 circuit breakers in the system were used to switch on and off the coupling and decoupling system at the time of voltage surge. This eliminated the influence of RLC elements on the shape and nature of the current in the tested system except when a surge occurred. The values of resistance (R1-R4), resistance-inductive (RL1 and RL2), and resistance-capacitive RC1 elements were selected on the basis of IEC 61000-4-5 [7] and summarized in Table 3.

Table 3. Values of elements of the coupling/decoupling system.

\begin{tabular}{|c|c|}
\hline Element & Value \\
\hline R1 & $1 \Omega$ \\
\hline R2 & $1 \Omega$ \\
\hline R3 & $1 \Omega$ \\
\hline R4 & $1 \Omega$ \\
\hline $\mathrm{RC} 1$ & $100 \Omega$ \\
\hline \multirow[b]{2}{*}{ RL1 } & $20 \Omega$ \\
\hline & $25 \mathrm{mH}$ \\
\hline RL2 & $\begin{array}{c}20 \Omega \\
25 \mathrm{mH}\end{array}$ \\
\hline $\mathrm{RC}$ & $\begin{array}{c}1 \Omega \\
15 \mu \mathrm{F}\end{array}$ \\
\hline
\end{tabular}

3.4. Computer Simulation Model of the Photovoltaic System Disturbed by a 1.2/50 $\mu \mathrm{s}$ Voltage Surge

The model tests covered the simulation of the operation of a PV system subjected to a $1.2 / 50 \mu$ s voltage surge with an amplitude of $1 \mathrm{kV}$.

The PV module, under the assumed test conditions generates a voltage of $29 \mathrm{~V} \mathrm{DC}$. The inverter converts the DC voltage into AC voltage with an effective value of $230 \mathrm{~V}$ and the quality parameters compliant with the power grid requirements. The amplitude value of the sinusoidal alternating current in the inverter circuit at the output of the output 
block section was about $0.8 \mathrm{~A}$. The voltage and current waveforms for the used inverter are presented in Figures 6 and 7.

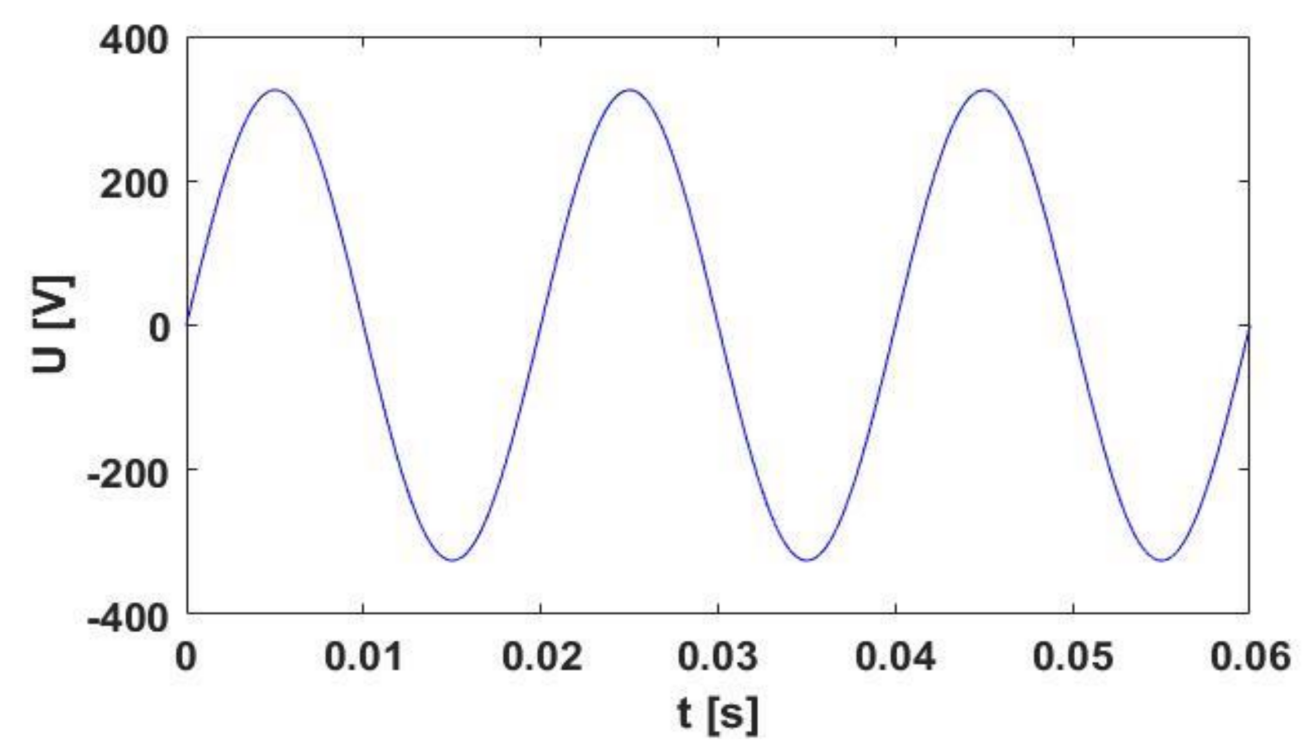

Figure 6. Input voltage waveform in the microinverter section.

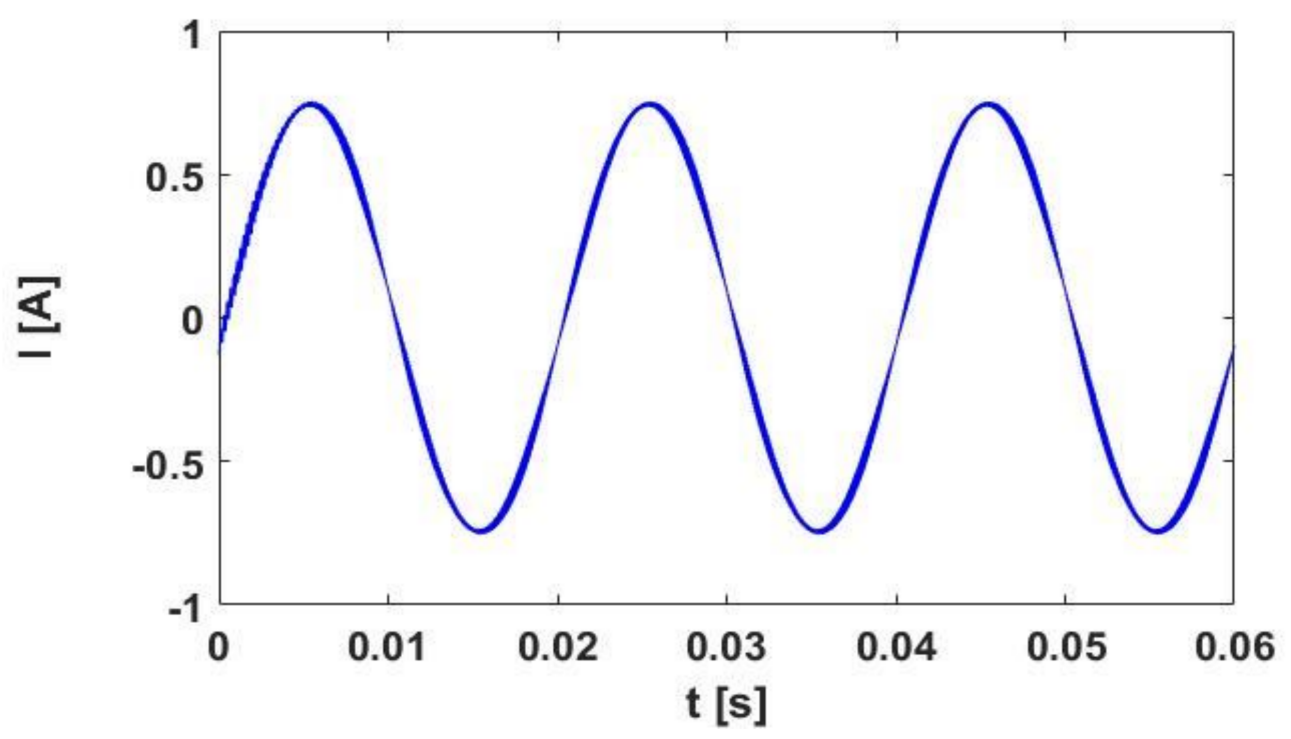

Figure 7. Input current waveform in the microinverter section.

In view of the conducted nature of surge disturbances, the disturbing pulse was introduced into the photovoltaic system from the side of the connection to the power grid.

The value of the surge voltage amplitude in the circuit was $1325 \mathrm{~V}$, while the value of the current amplitude at the moment of the surge was $38 \mathrm{~A}$ for the positive polarization, and for the negative polarization $-1325 \mathrm{~V}$ and $-36 \mathrm{~A}$ respectively. The modeled voltage and current waveforms are presented in Figure $8 \mathrm{a}, \mathrm{b}$ for the positive polarization and in Figures 9 and 10 for the negative polarization. 


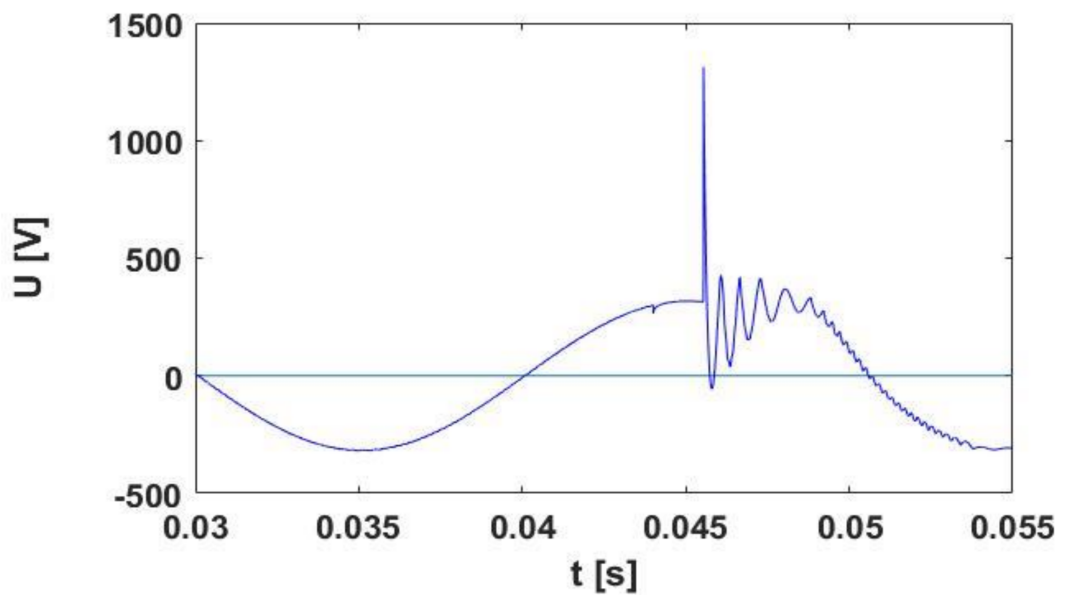

(a)

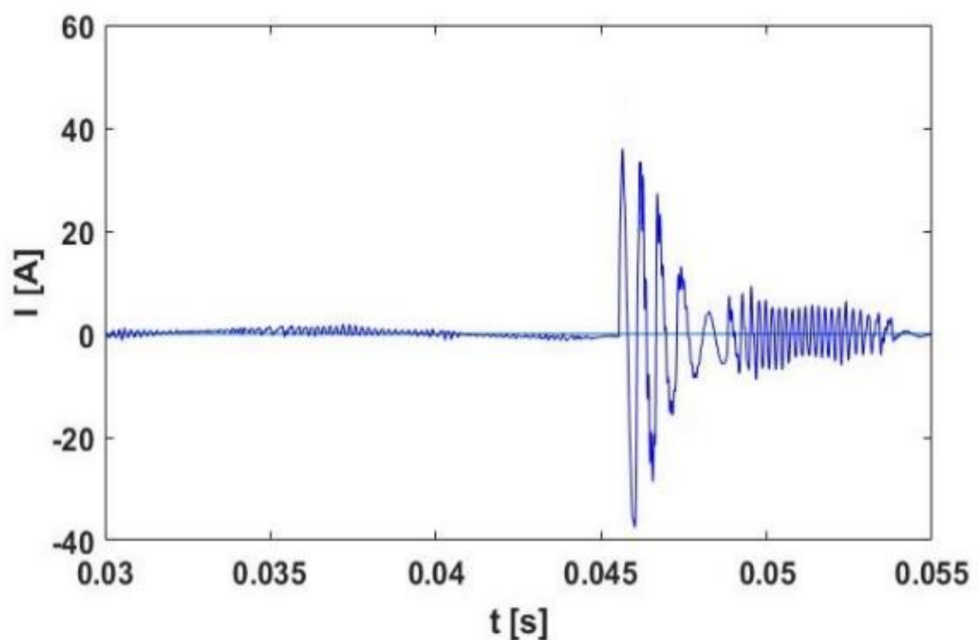

(b)

Figure 8. Input (a) voltage and (b) current waveform in the microinverter section disturbed by voltage surge with positive polarization.

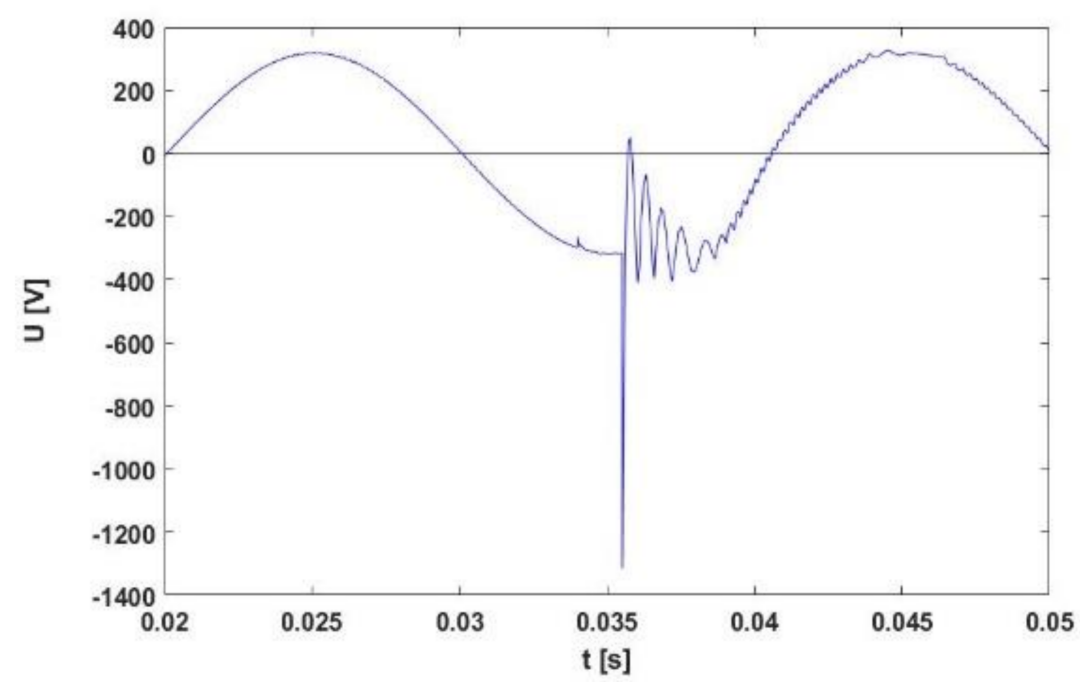

Figure 9. Input voltage waveform in the microinverter section disturbed by voltage surge with negative polarization. 


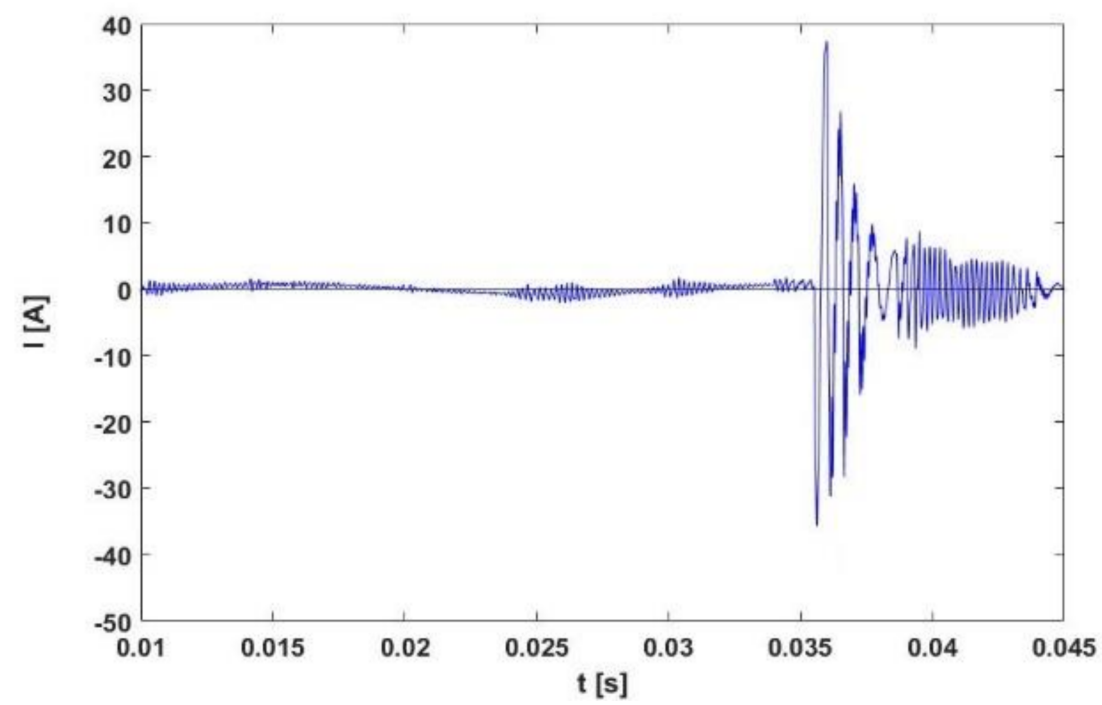

Figure 10. Input current waveform in the microinverter section disturbed by voltage surge with negative polarization.

The values of the current amplitudes at the moment of the surge were higher by $4750 \%$ for the positive polarization and $4500 \%$ for the negative polarization than the value of the amplitude of the current undisturbed by a voltage surge.

A current with such intensity may cause damage to the circuit. The voltage amplitude in the disturbed circuit was higher by $408 \%$ than the voltage amplitude in the non-disturbed circuit, equally for both polarizations.

As a complement, the authors also analyzed in Matlab/Simulink software current waveforms in three selected places of the tested system: behind the transformer and in the front of the rectifier bridge, before the $\mathrm{H}$-bridge and after the $\mathrm{H}$-bridge but before the grid filter (Figures 11-13). The highest value of the amplitude of the current signal at the moment of introducing the voltage surge occurred before the H-bridge, analyzing the system from the surge generator side towards the DC part of the installation. As a result, a damage of two metal-oxide-semiconductor-field-effect transistors in the H-bridge structure was found after verification of the tested microinverter.

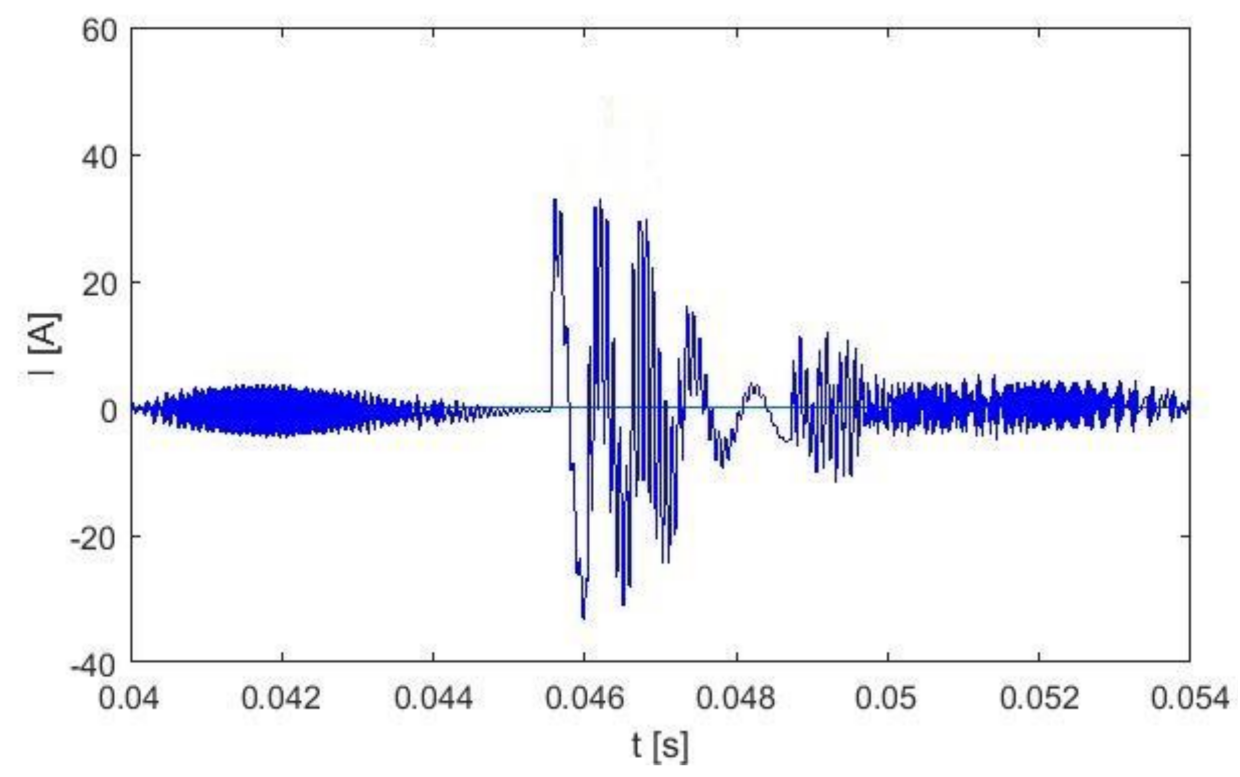

Figure 11. Current waveform between the H-bridge and grid filter. 


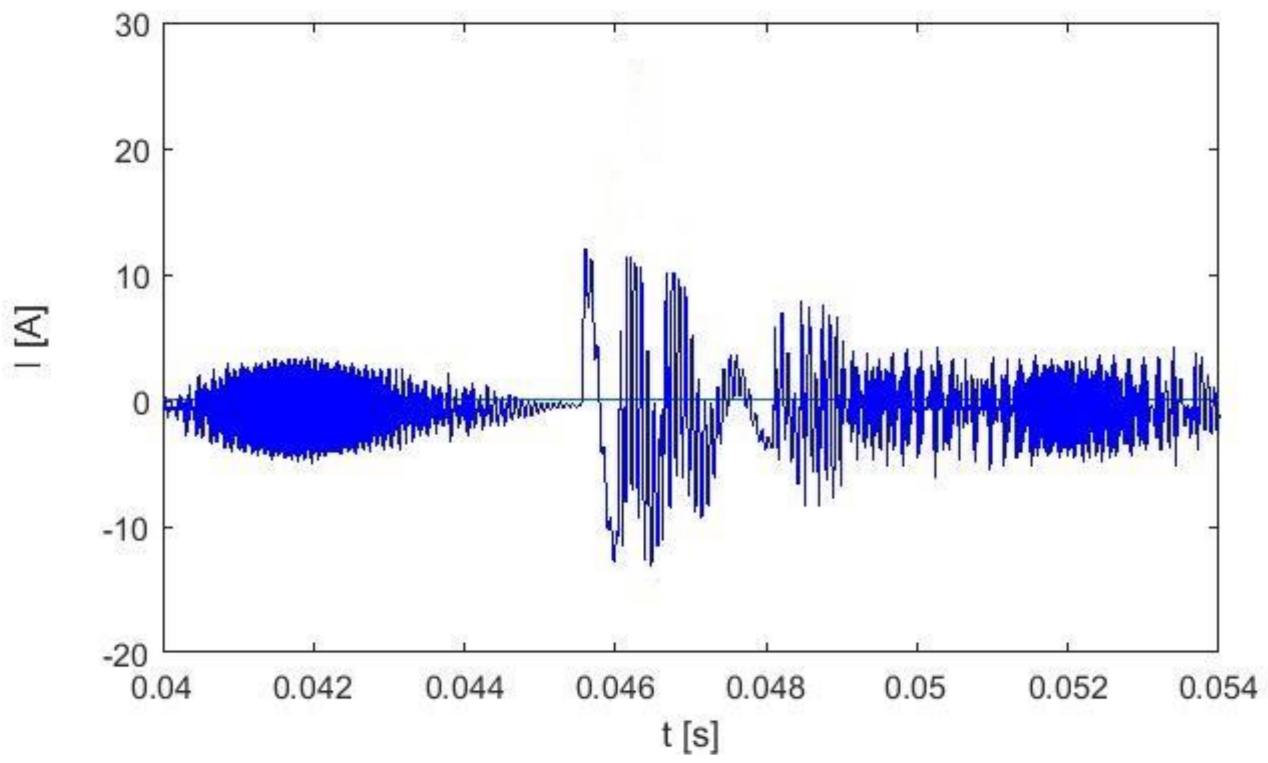

Figure 12. Current waveform between the H-bridge and Graetz bridge.

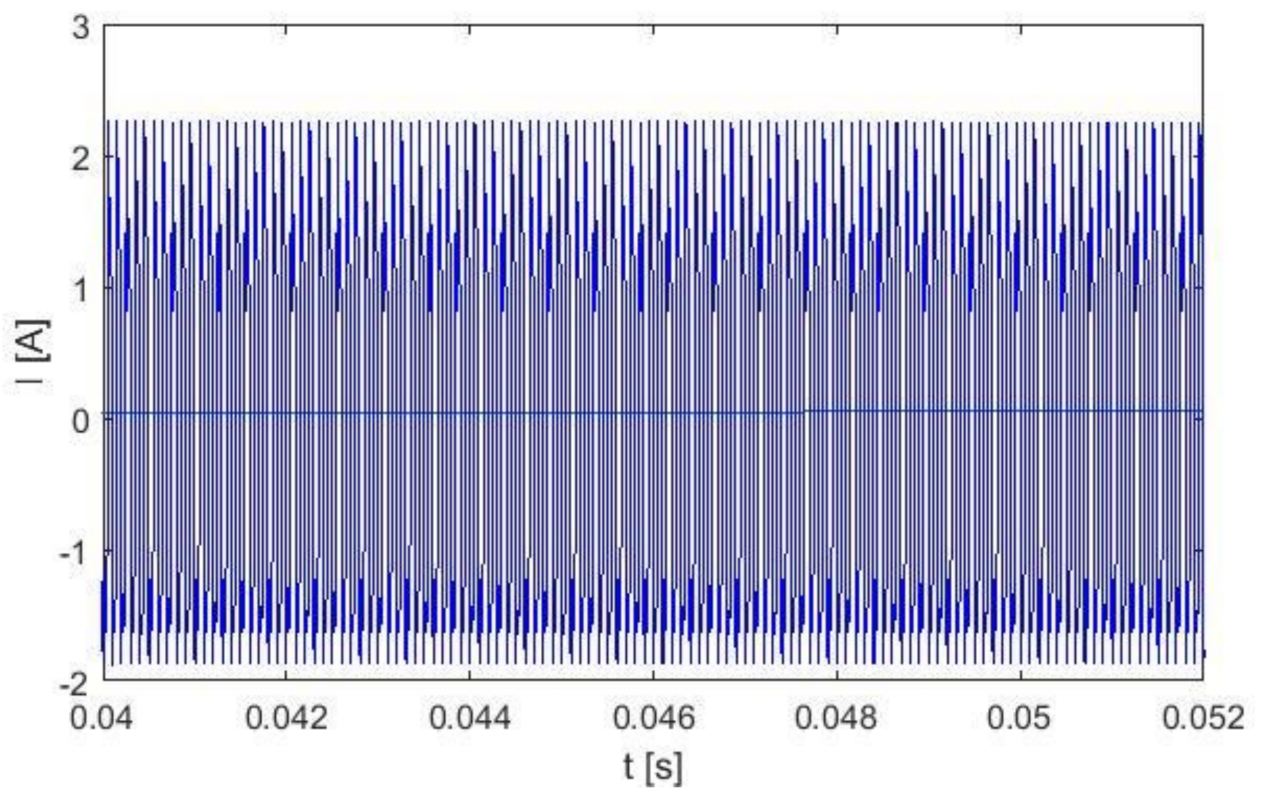

Figure 13. Current waveform between the Graetz bridge and transformer.

The analysis of the current signal, observed between the H-bridge and the rectifier, shows a significant reduction in its amplitude. Observations of the current signal behind the H-bridge indicate that the disturbance has been absorbed in the system. In this way, the effect of the introduced voltage disturbance, with the use of a surge generator, is not observed on the secondary side of the transformer.

\subsection{Laboratory Tests for Surge Immunity}

In order to confirm the correctness of the conducted computer simulation, a laboratory test stand was provided for the analyzed photovoltaic system. Figure 14 presents a part of the stand, which consists of the PV module lit with a set of halogen lighting fittings with a total power of $6 \mathrm{~kW}$. 


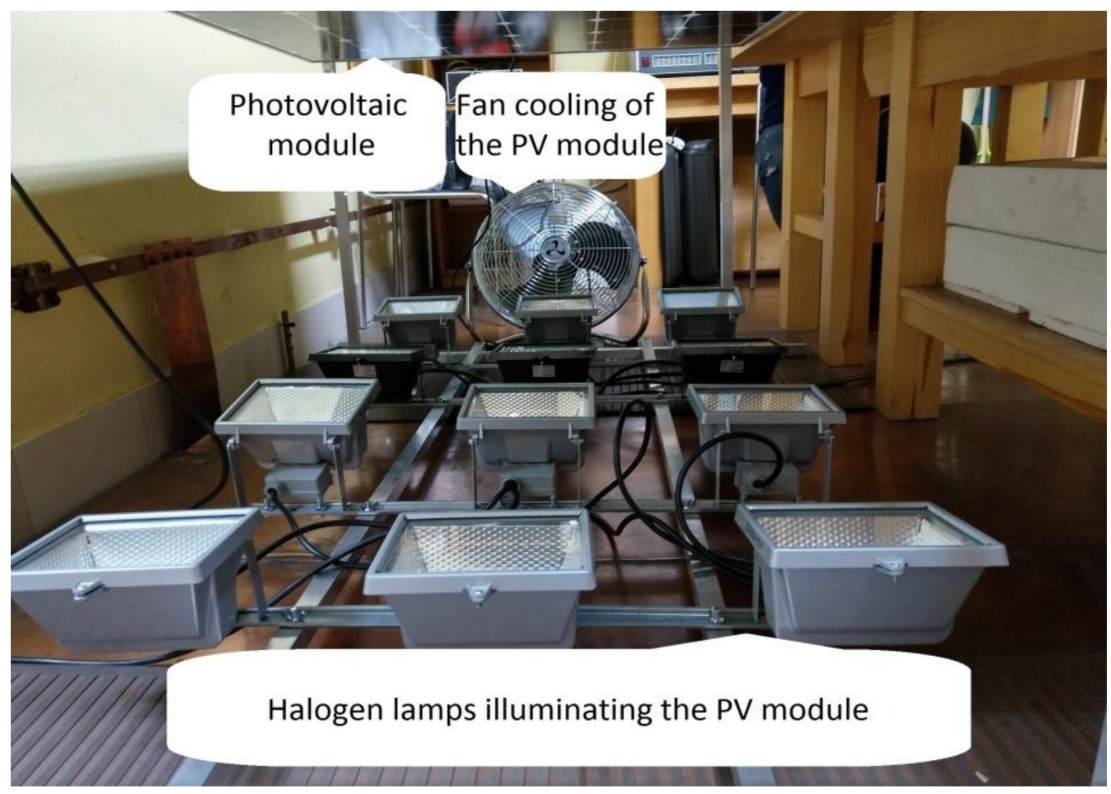

Figure 14. First part of the test stand consisting of a photovoltaic module, halogen lighting, and a cooling system.

In order to improve the quality of the power generated by the photovoltaic system, the system was cooled with an axial fan. For the improvement of the stand's mobility, the inverter was installed in a specially prepared case, which is presented in Figure 15.

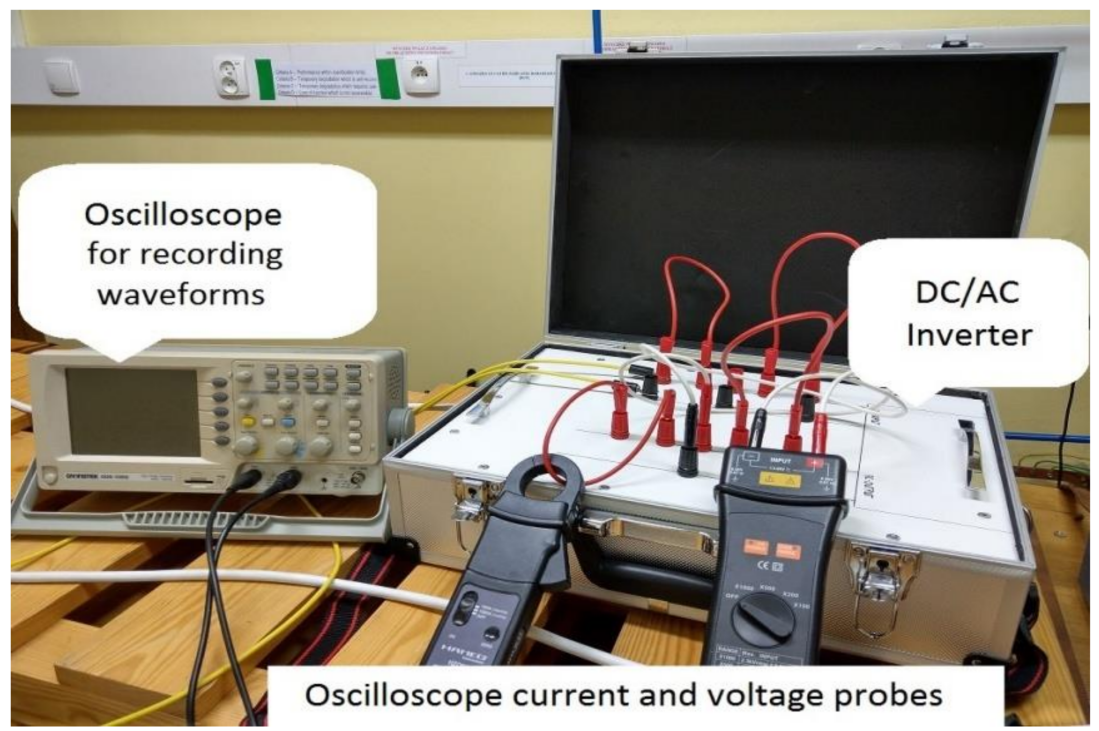

Figure 15. The second part of the test stand, consisting of a microinverter, voltage and current probes, and an oscilloscope.

Test results were recorded using probes (voltage and current probes) connected to an oscilloscope. The photovoltaic system was disturbed by a series of voltage surges obtained from a Teseq Schaffner 6150 generator, utilizing a coupling-decoupling network. Test results were recorded using two probes: voltage-Rigol RP1050D and current-Rigol RP1001C and a GW Instek GDS 10228 bit digital oscilloscope.

The parameters of the current and voltage probes are presented in Table 4. 
Table 4 . The values of selected parameters for the current and voltage probes.

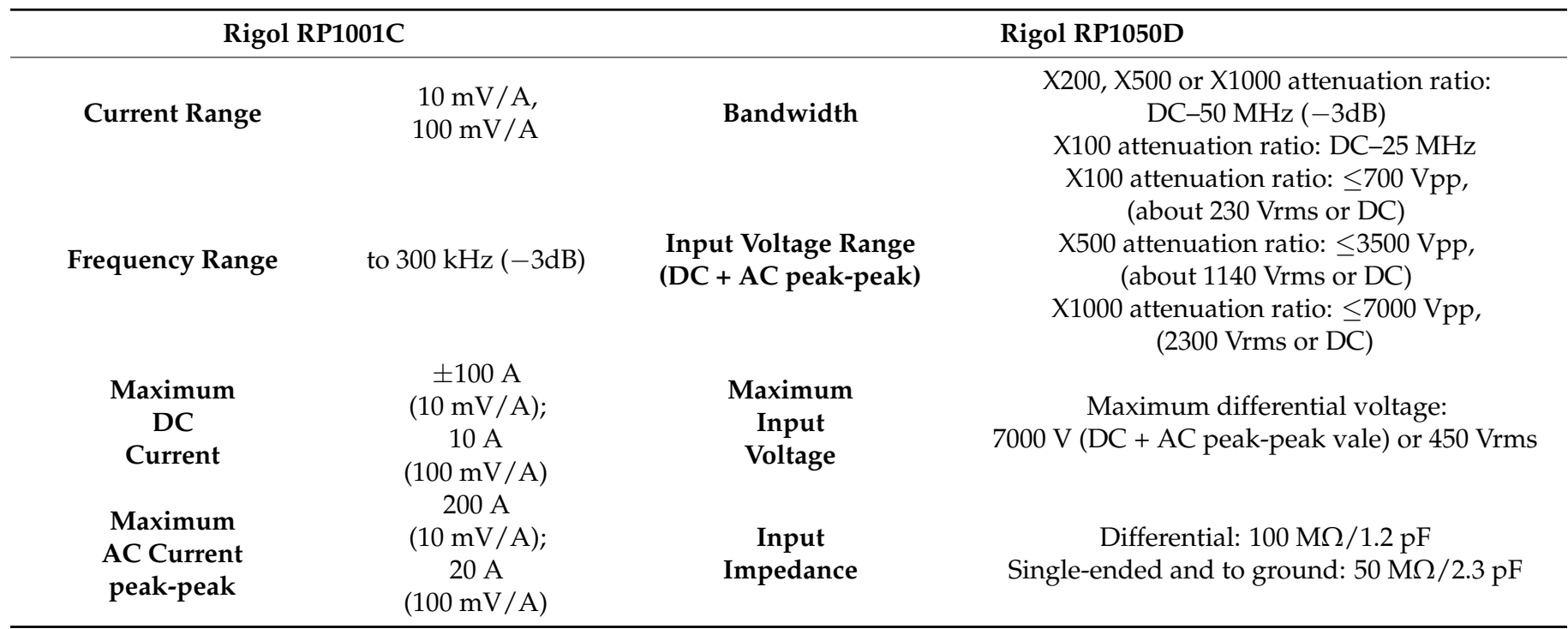

The first inverter was damaged during the first test; the second one was disturbed by a series of five pulses. The test results for the second inverter were listed in Table 5, and examples of the waveforms were presented in Figure 16, Figure 17, and Figure 18.

Table 5. The immunity test results of photovoltaic microinstallation disturbed by a $1.2 / 50 \mu \mathrm{s}$ voltage surge.

\begin{tabular}{ccccc}
\hline \multirow{2}{*}{$\begin{array}{c}\text { Measurement } \\
\text { Number }\end{array}$} & \multicolumn{2}{c}{ Positive Polarization } & \multicolumn{2}{c}{ Negative Polarization } \\
\cline { 2 - 5 } & I (A) & U (V) & I (A) & U (V) \\
\hline 1 & 44 & 1325 & -41 & -1325 \\
2 & 43 & 1325 & -42 & -1325 \\
3 & 43 & 1325 & -43 & -1325 \\
4 & 42 & 1325 & -42 & -1325 \\
5 & 43 & 1325 & -42 & -1325 \\
arithmetic & 43 & 1325 & -42 & -1325 \\
average & 43 & 1325 & -42 & -1325 \\
median & 0.63 & 0 & 0.63 & 0 \\
standard & & & & \\
deviation & & 0 & 1.5 & 0 \\
coefficient of & 1.47 & & &
\end{tabular}

In the laboratory tests, the authors focused on recording the amplitude of the current and voltage signal, in the form of the system response at the moment of introducing a voltage surge $1.2 / 50 \mu \mathrm{s}$. In order to accurately measure the value of the occurring pulse, the time and voltage divisions were set in such a way to record primarily this part of the obtained electrical signal in the form of a high-energy pulse. The current and voltage waveforms at the selected measuring point of the tested system were recorded using the oscilloscope function in the form of "peak detect".

The values of the voltage and current amplitudes obtained in laboratory tests and computer simulation tests were convergent. The simulated voltage values reached the same value, which was measured in the EMC laboratory, i.e., $\pm 1325 \mathrm{~V}$. The values of the currents obtained as a result of the computer simulation were $12 \%$ lower for the positive polarization of the $1.2 / 50 \mu$ s voltage surge and $15 \%$ lower for the negative polarization of the pulse than the values received in the laboratory tests. 


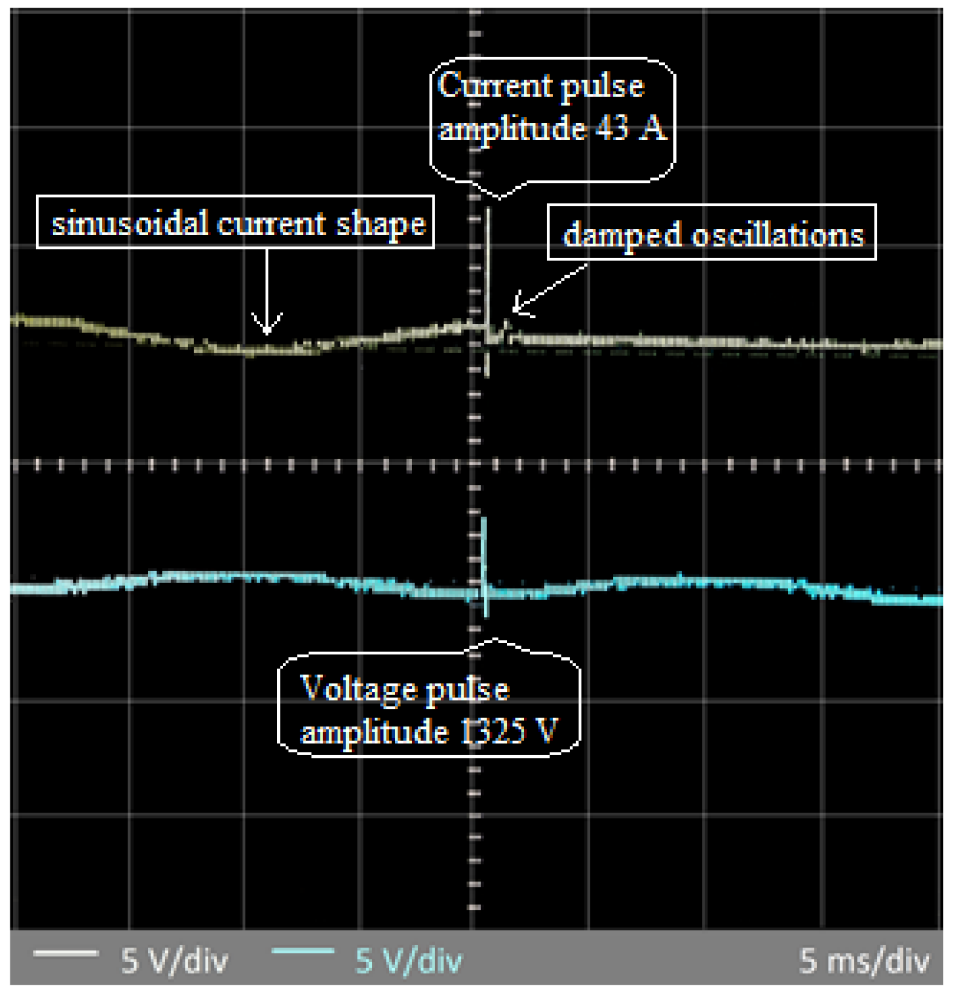

Figure 16. Current (yellow) and voltage (blue) waveform in a photovoltaic system disturbed by a $1.2 / 50 \mu$ s voltage surge with positive polarization.
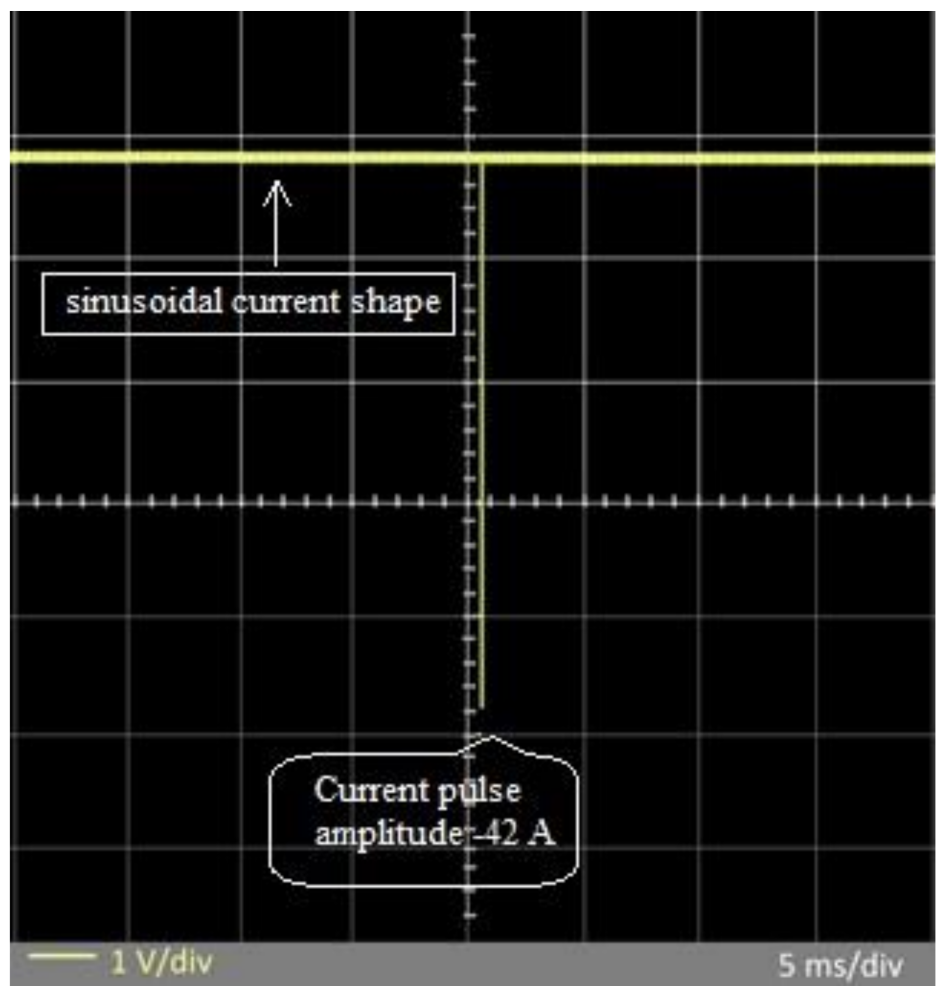

Figure 17. Current waveform in a photovoltaic system disturbed by a $1.2 / 50 \mu$ s voltage surge with negative polarization. 


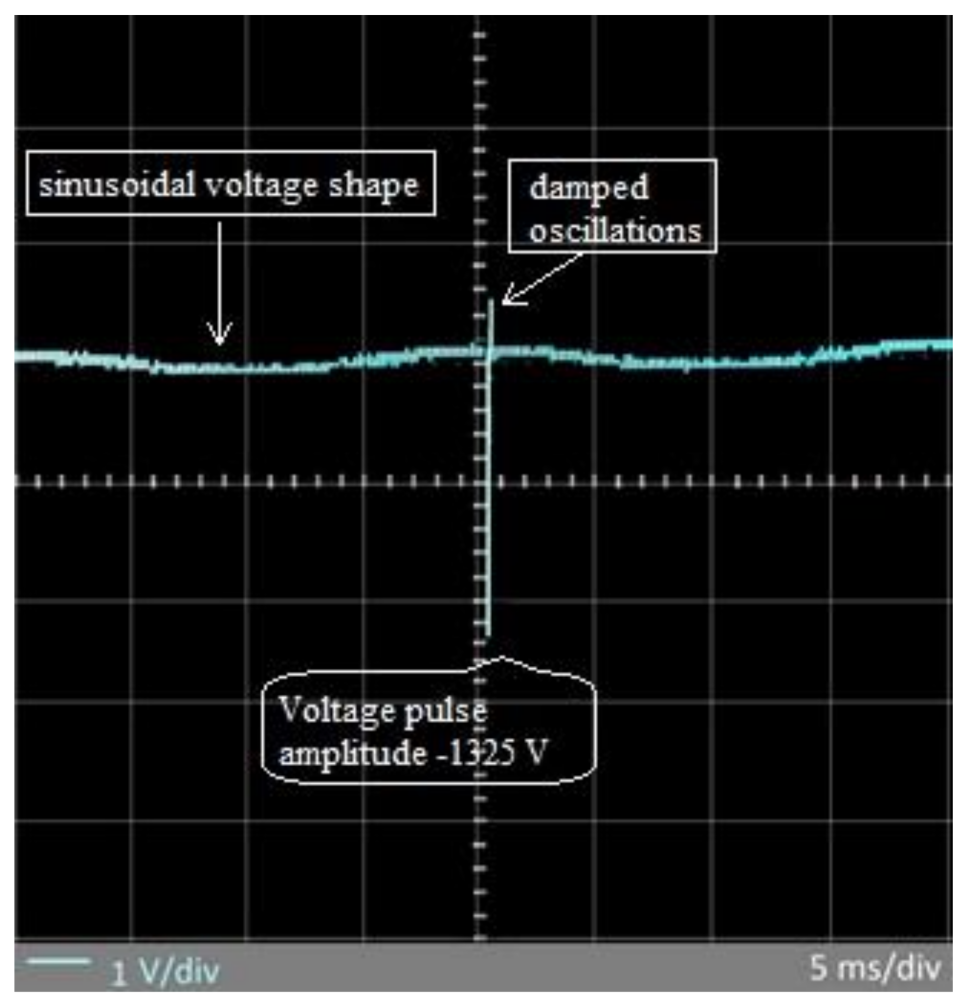

Figure 18. Voltage waveform in a photovoltaic system disturbed by a $1.2 / 50 \mu$ s voltage surge with negative polarization.

\section{Conclusions}

This article presents the simulation model of a photovoltaic microsystem, which is part of a fixed energy-saving building system. The model was made in the MATLAB/Simulink computer environment and the PV system was disturbed by a 1.2/50 $\mu$ s voltage pulse, not observed in other simulation studies. The $1.2 / 50 \mu$ s voltage surge pulse, generated by a modeled waveform generator was introduced using a modeled coupling/decupling network into the system from the power grid side. Significant changes in the value of the $\mathrm{AC}$ voltage and current were found in the DC/AC converter system.

The analysis of the obtained results of a computer simulation tests, presented in Figures 11-13, shows that the most sensitive elements of a photovoltaic installation were not the PV panels, exposed to direct lightning strikes, but DC/AC microinverters, converting direct voltage into the sinusoidal alternating form. The course of the current signal, caused by a voltage disturbance introduced from the power grid side, posed a threat to the electrical elements of the inverter structure, which are semiconductor transistors. On the basis of further verification, damage of two metal-oxide-semiconductor-field-effect transistors in the H-bridge structure was found. Transistor failures frequently occur in PV microinverters operating in high-voltage, high-current, or extreme temperature conditions exceeding the manufacturer's specification.

In general, microinverters from the DC side are exposed to both overvoltage induced in series connected PV modules and partial lightning currents that can penetrate into the installation during direct discharge. On the AC side, the DC/AC inverter may be exposed to overvoltages in the power grid, especially when the main building electrical switchgear is not properly protected.

For this reason, in accordance with the PN-HD 60364-7-712: 2016-05 standard, it is recommended to use multistage protection devices in the photovoltaic installation like surge protection devices (SPDs) of the appropriate type. In many cases, it is recommended to use SPD before (DC side of the photovoltaic installation) and after (AC side of the installation) the inverter and when the distance between the PV generator and the inverter 
exceeds $10 \mathrm{~m}$ also in close distance to PV modules. These protections are designed to protect sensitive devices against the discharge current (current signal shape $8 / 20 \mu \mathrm{s}$ ), surge current $(10 / 350 \mu \mathrm{s})$, and voltage surge $(1.2 / 50 \mu \mathrm{s})$. Paying attention to the proper protection of photovoltaic inverters in order to ensure their long-term and failure-free operation is an essential element in designing a highly efficient installation.

The conducted simulation studies, supplemented by EMC laboratory tests, of a photovoltaic microinstallation, consisting of a photovoltaic module and an individual voltage inverter, showed that in the event of an external surge disturbance spreading from the AC power grid side towards the constant voltage part of the electrical installation, the photovoltaic generator has the ability to continue generating and delivering electric power during periods of intense stress on energy system. Results do not indicate the propagation of the disturbance in the photovoltaic module section. Multiple introductions of the $1.2 / 50 \mu$ s voltage surge caused no damage to the photovoltaic solar cells. Additional tests performed to verify the applied photovoltaic module, determining its current-voltage characteristics, including thermovision examination of the silicon cells structure, confirmed its good condition. It can be concluded that in the situation of a voltage disturbance propagating from the power grid side, which is the place where the photovoltaic installation is connected, the section of the photovoltaic generator will not be affected by its effects.

The results of the computer simulation were verified using a specially built test stand. The test was carried out in an accredited electromagnetic compatibility laboratory. It was also confirmed that the MATLAB/Simulink simulation environment is a useful tool for the development of circuit models of electrical and electronic systems subjected to the impacts of electromagnetic surge disturbances described in IEC 61000-4-5. The software allows for very good mapping of the real elements of the system and devices.

The circuit was tested in the EMC laboratory using two identical inverters. The first of them was damaged during the test. This confirms the usefulness of performing simulation tests of electromagnetic compatibility. The PV modules and the DC/AC power electronic converters cooperating with them are potentially exposed to damage as a result of the direct impact of the lightning discharge and couplings with objects located in the direct vicinity. Therefore, it is necessary to protect devices, which are part of a photovoltaic system, located on the walls of buildings and other structures, due to the threat of a lightning discharge.

Good compatibility of simulation and measurement results indicates that the computer simulation can in some cases be an alternative to laboratory EMC tests, especially those where damage or destruction of the ETU is possible. Moreover, computer simulation of EMC immunity tests can be especially useful at the design stage of new electronic/electrical devices. Contrary to laboratory tests computer simulation models (including the ETU model) allow one to simulate (measure) voltages across and currents through each element of the model, thus enabling potential problems to be identified before laboratory/site testing becomes practicable or possible.

Photovoltaic systems, like all energy systems, must be constantly developed in order to improve resilience. They need to simultaneously withstand extreme conditions that cause grid power disruptions, be configured in a way that allows electricity to be delivered with required quality parameters, and overcome disruptions arising from solar resource intermittency. One of the methods to obtain resilience can be a hybrid configuration of the photovoltaic installation in which photovoltaic modules can cooperate with electrochemical energy storage units via a hybrid DC/AC inverter in switchable on-grid and island topology. The energy storage unit is an additional separation between the photovoltaic generator and the electricity grid. During the disturbance appropriate control systems will enable further correct operation and energy transfer to the energy storage unit. This enables the continuity of power supply to priority receivers and increases energy self-sufficiency. Photovoltaic system can act as a self-sufficient microgrid.

The presented paper does not exhaust all the EMC immunity issues. It discusses the modeling and simulation of one selected stationary installation for one selected type of a conducted disturbance-voltage surge. There remain many other types of electromagnetic 
disturbances that may have a significant impact on the operation of electronic equipment. This provides inspiration for further research work involving, among other things, the development of a simulation model of an "EFT/Burst" fast electrical transient generator, which, together with a "surge" voltage surge generator, usually constitutes a single laboratory device controlled for appropriate tests by computer software.

In subsequent studies, the authors plan to use numerous photovoltaic inverters that also have IGBT (insulated gate bipolar transistor). The authors will also make a detailed computer and experimental analysis of two more microinverters topologies like H5 and HERIC.

It should also be emphasized that the simulation and physical tests presented in the work are limited to the testing of selected devices in the form of modern and widely used components of photovoltaic installations. Research on the correct functioning of photovoltaic microinverters, during the occurrence of disturbances in the form of voltage surges, is particularly important for the energy efficiency of a complete photovoltaic installation. Inverters are an essential part of a solar installation. They also have a significant share in the overall costs and economic balance. Microinverters improved reliability compared to central inverters due to lower power processing requirements for switches. A microinverter is typically connected to a single photovoltaic module and optimize its operation. There are significant advantages of deploying microinverters. Unlike a central inverter, if a single microinverter fails, only a single solar module will not convert solar energy into electric energy. In the case of central inverters, the entire installation stops delivering power to the load or AC grid. Microinverters have also a better performance ratio compared to string and central inverters in case of high shading effect. Improvement in the reliability of solar photovoltaic inverters is a growing research area. Functional failures associated with microinverters can decrease the return on investment (ROI) parameter. Unfortunately, microinverters warranties are most often less than 15 years, whereas the PV modules are described by a twenty-five year warranty period.

Author Contributions: Conceptualization, D.B., A.B. and W.M.; methodology, D.B., W.M.; simulation, D.B. and A.B., testing, D.B.; validation, W.M.; formal analysis, D.B., A.B. and W.M.; investigation, D.B.; writing—original draft preparation, D.B., A.B. and W.M.; writing—review and editing, W.M. All authors have read and agreed to the published version of the manuscript.

Funding: This research received no external funding.

Institutional Review Board Statement: Not applicable.

Informed Consent Statement: Not applicable.

Data Availability Statement: Not applicable.

Conflicts of Interest: The authors declare no conflict of interest.

\section{References}

1. European Parliament. Electromagnetic compatibility (EMC) Directive 2014/30/EU. Off. J. Eur. Union 2014, L96, 79-106.

2. Bugala, D.; Bugala, A. Immunity of photovoltaic installation on electromagnetic surge disturbances. In Proceedings of the ITM Web of Conferences, Computer Applications in Electrical Engineering (ZkwE 2019), Poznań, Poland, 15 April 2019; Volume 28, p. 01034.

3. Typanska, D.; Machczynski, W. Immunity test of the lighting installation for electromagnetic surge disturbances. In Proceedings of the ITM Web of Conferences, Computer Applications in Electrical Engineering (ZkwE 2018), Poznań, Poland, 23-24 April 2018; Volume 19, p. 01011.

4. Bednarek, K.; Typanska, D.; Misiorny, J.; Pietkiewicz, A. Reduction of electromagnetic disturbances emission generated by LED lighting fixture. In Proceedings of the 2018 Applications of Electromagnetics in Modern Techniques and Medicine (PTZE), Racławice, Poland, 9-12 September 2018; Volume 1, pp. 13-16.

5. Paul, C.R. Introduction to Electromagnetic Compatibility, 2nd ed.; Wiley: Hoboken, NJ, USA, 2006.

6. Holland, I.; Doorsamy, W.; Nixon, K. Analysis of lightning surge effects on small-scale rooftop photovoltaic systems. In Proceedings of the 2018 Power Systems Computation Conference (PSCC), Dublin, Ireland, 11-15 June 2018; Volume 1, pp. 1-6.

7. International Electrotechnical Commission. Electromagnetic Compatibility (EMC)_Part 4-5: Testing and Measurement TechniquesSurge Immunity Test; IEC TR 61000-4-5: 2014+A1:2017; International Electrotechnical Commission: Geneva, Switzerland, 2017. 
8. Zaini, N.H.; Ab-Kadir, M.Z.A.; Izadi, M.; Ahmad, N.I.; Radzi, M.A.M.; Azis, N.; Wan Hasan, W.Z. On the effect of lightning on a solar photovoltaic system. In Proceedings of the 2016 33rd International Conference on Lightning Protection (ICLP), Estoril, Portugal, 25-30 September 2016; Volume 1, pp. 1-4.

9. Mehta, S.; Basak, P.; Anelis, K.; Paramane, A. Simulation of single and multistage impulse voltage generator using Matlab Simulink. In Proceedings of the 2018 International Conference on Computing, Power and Communication Technologies (GUCON), Greater Noida, India, 28-29 September 2018; Volume 1, pp. 641-646.

10. Le, T.; Colin, H.; Shakarchi, F.; Quoc, T.T. Improved Matlab Simulink two-diode model of PV module and method of fast large-scale PV system simulation. In Proceedings of the 2018 7th International Conference on Renewable Energy Research and Applications (ICRERA), Paris, France, 14-17 October 2018; Volume 1, pp. 982-985.

11. Bhattacharya, S.; Mondal, A. Prototype development of an SPWM inverter for PV application on dSPACE platform. In Proceedings of the 2016 IEEE First International Conference on Control, Measurement and Instrumentation (CMI), Kolkata, India, 8-10 January 2016; Volume 1, pp. 435-439.

12. Patil, S.P.; Patil, R.R.; Mulla, A.M.; Patil, S.D. Performance analysis of interleaved flyback inverter topology for single phase high power application using MATLAB Simulink. In Proceedings of the 2017 International Conference on Circuit, Power and Computing Technologies (ICCPCT), Kollam, India, 20-21 April 2017; Volume 1, pp. 1-5.

13. Carvalho, T.; Salazar, N.; Lock, A. An analog based control scheme applied in stand-alone photovoltaic systems for DC power distribution. Renew. Sustain. Energy Rev. 2019, 110, 236-246. [CrossRef]

14. Zaini, N.; Ab-Kadir, A.; Radzi, M.; Azis, N.; Ahmad, N.; Nasir, M.; Izadi, M.; Aziz, N.; Ali, Z. Lightning surge on the DC and AC side of solar PV system. In Proceedings of the 2019 11th Asia-Pacific International Conference on Lightning (APL), Hong Kong, China, 12-14 June 2019.

15. Ahmad, N.; Ab-Kadir, A.; Izadi, M.; Aziz, N.; Radzi, M.; Zaini, N.; Nasir, M. Lightning protection on photovoltaic systems: A review on current and recommended practices. Renew. Sustain. Energy Rev. 2018, 82, 1611-1619. [CrossRef]

16. Baba, Y.; Rakov, V.A. Electromagnetic Computation Methods for Lightning Surge Protection Studies, 1st ed.; Wiley: Singapore, 2016.

17. Amara, M.; Vollaire, C.; Ali, M.; Costa, F. EMC modeling of a three phase inverter. In Proceedings of the EMC EUROPE, Amsterdam, The Netherlands, 27-30 August 2018; Volume 1, pp. 642-647.

18. Bauer, S.; Renhart, W.; Bíró, O.; Türk, C.; Maier, C.; Winkler, G.; Deutschmann, B. Investigation of Spice models for overvoltage protection devices with respect to fast transients. IEEE Lett. Electromagn. Compat. Pract. Appl. 2019, 1, 20-25. [CrossRef]

19. Penalver, P.L.F.; Braga, E. Simulation of surge protection for a direct current circuit. Int. J. Electr. Comput. Eng. 2017, 11, 1-5.

20. Bokoro, P.; Doorsamy, W. Investigation of lightning surge effects on a grid-connected PV plant. In Proceedings of the 2018 IEEE International Conference on High Voltage Engineering and Application (ICHVE), Athens, Greece, 10-13 September 2018; Volume 1, pp. 1-4.

21. Charalambous, C.; Kokkinos, N.; Christofides, N.; Ab Kadir, M.; Gomes, C. A simulation tool to assess the lightning induced over-voltages on dc cables of photovoltaic installations. In Proceedings of the 2014 International Conference on Lightning Protection (ICLP), Shanghai, China, 11-18 October 2014; Volume 1, pp. 1571-1576.

22. Carobbi, C.; Bonci, A. Elementary and ideal equivalent circuit model of the 1,2/50-8/20 us combination wave generator. IEEE Electromagn. Compat. Mag. 2013, 2, 51-57. [CrossRef]

23. Markowska, R.; Sowa, A.; Wiater, J. Simulation testing of lightning threats to electronic systems. Prz. Elektrotech. 2010, 86, 146-149.

24. Masłowski, G.; Ziemba, R. Measurements and modeling of electromagnetic disturbances in the lightning protection system of the residential building. Prz. Elektrotech. 2016, 92, 64-67. [CrossRef]

25. Masłowski, G. Lightning Analysis and Modeling for Surge Protection; Dissertations, Monographs Series; AGH University of Science and Technology Publishing House: Krakow, Poland, 2010.

26. Masłowski, G. Contemporary trends in modeling lightning discharges-Theory and applications. Prz. Elektrotech. 2010, 86, 308-312.

27. Rameli, N.; Ab-Kadir, M.Z.A.; Izadi, M.; Gomes, C.; Azis, N. Variations in return stroke velocity and its effect on the return stroke current along lightning channel. In Proceedings of the 2016 33rd International Conference on Lightning Protection (ICLP), Estoril, Portugal, 25-30 September 2016; Volume 1, pp. 1-5.

28. Zhang, G.; Chen, M.; Du, Y. Representation of lightning return stroke channel in FDTD code and its impact on lightning-produced electric field calculation. In Proceedings of the 2018 34th International Conference on Lightning Protection (ICLP), Rzeszow, Poland, 2-7 September 2018; Volume 1, pp. 1-5.

29. Yu, J.L.; Fan, Y.D.; Wang, J.G.; Zhou, M.; Cai, L.; Huang, S.B.; Hu, C. Influence of channel length, return-stroke speed and ground conductivity on horizontal electric field associated with nearby lightning return strokes. In Proceedings of the 2014 International Conference on Lightning Protection (ICLP), Shanghai, China, 11-18 October 2014; Volume 1, pp. $205-209$.

30. Standler, R. Equations for some transient overvoltage test waveforms. IEEE Trans. Electromagn. Compat. 1988, 30, 69-71. [CrossRef]

31. Kaiser, K.L. Electromagnetic Compatibility Handbook; CRC Press: Boca Raton, FL, USA, 2005.

32. Bugala, A.; Frydrychowicz-Jastrzebska, G.; Zbytek, Z.; Dach, J.; Janczak, D. Long-term performance evaluation of a fixed and solar follow-up systems with modified astronomical positioning in Polish conditions. In Proceedings of the 2016 International Conference on Frontiers of Sensors Technologies (ICFST 2016), Hong Kong, China, 12-14 May 2016; Volume 59, pp. 1-6. 
33. Bugala, A.; Zaborowicz, M.; Boniecki, P.; Janczak, D.; Koszela, K.; Czekala, W.; Lewicki, A. Short-term forecast of generation of electric energy in photovoltaic systems. Renew. Sustain. Energy Rev. 2018, 81, 306-312. [CrossRef]

34. Haberlin, H. Photovoltaics. System Design and Practice, 1st ed.; Wiley: Chichester, UK, 2012. 